\title{
Bonuses and Non-Public Information in Publicly Traded Firms*
}

\author{
Rachel M. Hayes and Scott Schaefer \\ Kellogg Graduate School of Management \\ Northwestern University
}

January 24, 2000

${ }^{*}$ We thank seminar participants at Chicago, Michigan, Wharton and Wisconsin for comments. Hayes: Department of Accounting and Information Systems. E-mail: r-hayes@nwu .edu. Phone: (847) 491-2662. Schaefer: Department of Management and Strategy. E-mail: s-schaefer@nwu.edu. Phone: (847) 467-6598. Fax: (847) 467-1777. Address: 2001 Sheridan Road, Evanston, IL 60208-2013. 


\title{
Bonuses and Non-Public Information in Publicly Traded Firms
}

\begin{abstract}
The literature on relational incentive contracts suggests that firms may be able to condition payments to employees on information that is not available to those outside the firm. Given this, market participants may use the magnitude of such payments to infer the non-public information, which then may give firms a reason to choose wage payments strategically. We combine the literatures on relational incentive contracts (from labor economics) and signaling to financial markets (from finance) and examine equilibria of a signaling game in which payments from a firm to a manager convey information regarding the firm's future cash flows. Our model reveals how the nature of the firm's relationship with its manager is affected by the firm's incentive to choose wage payments strategically. We discuss implications of our model for firms' choices over the mix of compensation instruments for top executives, as well as possible effects of executive compensation disclosure rules.
\end{abstract}




\section{Introduction}

Administering performance measurement and reward systems for top managers is a primary task of corporate boards of directors. Meetings of the full board, committee meetings, and direct communication with the firm's employees give board members a more complete view of managers' actions and opportunities than is available to outsiders. As better performance measurement can improve the provision of incentives, directors should presumably make use of all information - including market- and accounting-based measures of firm performance, but also information gained through direct monitoring that may not be publicly available in assessing a manager's performance. Indeed, compensation committee reports contained in firms' proxy statements frequently indicate that managers' bonus amounts depend on subjective or strategic factors that are not revealed to outsiders. ${ }^{1}$

Our objective in this paper is to examine implications of the use of non-public information in performance measurement and reward systems for managers of publicly traded firms. The idea underlying our analysis is the following: Suppose boards of directors gather non-public information to measure the performance of top managers, use such information in rewarding managers, and the payments made to top managers are observed by market participants. Then, market participants may use the magnitude of payments made to managers to infer the nonpublic information. Given this, boards of directors may face an incentive to choose wage payments strategically, in order to affect outsiders' assessments of the firm's prospects. We study equilibrium wage contracts that arise in this setting.

We proceed by combining two lines of existing research, one each from labor economics and finance. The possibility that incentive contracts may be based on information observed by only the contracting parties is the subject of a growing literature in labor economics on implicit or relational incentive contracts. While much research on incentive contracting focuses on performance measures that can be verified by external third parties, work on implicit or relational contracts emphasizes the role of reputation as an alternative enforcement mechanism (see Holmstrom (1983) or Bull (1987)). If reputation, rather than recourse to the legal system,

\footnotetext{
${ }^{1}$ According to recent proxy statements, Sun Microsystems bases managers' pay on performance measures that are "competitively sensitive," while Thermo Electron applies a "subjective evaluation of the contributions of each executive that are not captured by operating measures but are considered important to the creation of long-term value." Bushman, Indjejikian and Smith (1996) and Ittner, Larcker and Rajan (1997) use survey responses and proxy disclosures, respectively, to study the extent to which managerial pay depends on individual-based or non-financial performance measures that may not be available to those outside the firm.
} 
governs contracts, then performance measures need not be verifiable by, or even observable to, outsiders. Baker, Gibbons and Murphy (1994) and Levin (1998) study reputation-based incentive contracting when some performance measures are not verifiable. Hayes and Schaefer (1999) provide empirical evidence consistent with the hypothesis that firms use non-public information in rewarding top managers by showing that variation in current managerial pay that is unexplained by current firm performance is useful in predicting future firm performance.

Similarly, a large literature in finance examines ways in which various corporate actions can convey information to financial markets. If there is a one-to-one mapping from private information to corporate actions, then market participants may attempt to infer the information upon observing the action. This then implies a mapping from actions to market valuation, which gives firms an incentive to try to manipulate outsiders' perceptions by choosing actions strategically. Ross (1977) and Leland and Pyle (1977), for example, study signaling models of capital structure, while Bhattacharya (1979) and Miller and Rock (1985) develop dividendsignaling models. More recently, Kanodia and Lee (1998) examine information transmission through investment and the role of periodic performance reports in mitigating incentives for inefficient signaling.

We draw on these literatures by embedding a simple agency model in a repeated-game-based model of reputation, and then asking how relational incentive contracts are affected when market participants base inferences regarding the firm's future cash flows on the magnitude of payments made to the agent. In the stage game, a firm seeking to maximize the average payoff to its original shareholders contracts with a manager whose hidden effort increases the likelihood that the firm's project is successful. Immediately after the manager's effort choice, the firm and the manager privately observe the project outcome. The firm chooses whether to pay the manager a bonus, and the magnitude of this bonus payment is observed by stock market participants. A round of trading in the firm's stock follows. Following the dividend-signaling model of Miller and Rock (1985), we assume that a predetermined fraction of the firm's original shareholders sell their shares at this time. After this round of trading, the outcome of the firm's project is revealed, and the payoff from the project is paid out to shareholders. This stage game is repeated infinitely, and the firm and manager are allowed to condition current actions on the past history of play.

This framework imposes two constraints - beyond the normal individual rationality and incentive compatibility constraints — on the solution to the agency problem. A no-mimic constraint arises from the fact that, in equilibrium, firms with failed projects must not find it 
worthwhile to attempt to fool market participants by paying the bonus associated with success. A reputational governance constraint arises because equilibrium bonus payments cannot be so large that the firm prefers to renege on its commitment to pay the bonus. Our inquiry focuses on how these two constraints interact to affect equilibrium bonus contracts.

We structure our analysis by studying each of these two constraints in isolation, and then merging these analyses into a single model. We develop the no-mimic constraint by examining the stage game under the assumption that some unmodeled governance mechanism is sufficiently strong to permit the firm to commit to the second-best contract. In this setting, we show that the size of the bonus payment in the equilibrium contract increases as the firm becomes more myopic (that is, as the pre-determined fraction of original shareholders intending to sell at the first round of trading increases). When the firm is not so myopic, the bonus associated with the second-best contract is sufficiently large to deter firms with failed projects from paying this bonus in an attempt to fool the market. However, as the firm's degree of myopia increases, the second-best contract may no longer satisfy the no-mimic constraint; equilibrium then requires a bonus that is too high relative to the second best. As myopia increases further, the risk and effort costs associated with such large bonuses can become prohibitive, and the equilibrium contract may feature pooling and full insurance for the manager.

We develop the reputational governance constraint by repeating this stage game infinitely, under the assumption that the firm has no concern for short-run share prices. As in other repeated-game models of reputation, the maximum feasible bonus in this case is determined by the firm's comparison of the immediate savings from reneging on a promised bonus payment and the gains from future cooperation foregone as a result of reneging.

Combining these benchmark models, we characterize how the set of feasible bonus contracts varies with the firm's degree of concern for short-run share prices. Our primary finding is that this relationship is non-monotonic: the largest feasible bonus amounts may increase or decrease as the firm becomes more myopic. This result arises because of the role of the no-mimic constraint as an alternative governance mechanism - a firm that has reneged on a relational contract in the past can still credibly commit to pay the smallest bonus that satisfies the no-mimic constraint in the event of project success. As the firm becomes more myopic, this no-mimic bonus increases, and the contracting environment facing the firm and the manager in the event that the firm reneged becomes more attractive. This reduces the value of the firm's reputation, and limits the efficacy of reputation as a governance mechanism. When the firm becomes very eager to signal, this "fallback" contracting environment may be suffi- 
ciently attractive so that no reputationally governed contracts are feasible. In this case, the no-mimic constraint provides the only credible governance mechanism, so the largest feasible bonus amounts increases with myopia.

Because the nature of the firm's relationship with its manager is affected by the firm's incentive to choose wage payments strategically, we obtain quite different results from those usually found in models where corporate actions convey value-relevant information. In most signaling models featuring myopic corporate behavior, firms take actions that hurt long-run profitability in a (futile, in equilibrium) attempt to increase short-run share prices. As the firm becomes more focused on short-term share prices, it engages in more of such activity, which results in even lower profits. Our model yields different results on two dimensions. First, we find that as the firm becomes more focused on short-run share prices, it may engage in less of the signaling activity, which in this case is paying bonuses for project success. As in more standard signaling models, increases in myopia are, in this case, associated with reductions in profits. Second, while we do identify conditions under which increases in myopia lead to higher levels of the signaling activity, we find that profits may actually increase with myopia in these cases. These results arise because, in our model, there are potentially two sources of inefficiency associated with the firm's use of non-public information. The first stems from the the firm's incentive to behave strategically, while the second arises because of difficulties in enforcing contracts based on non-public information. We show that the firm's incentive to choose wage payment strategically can either exacerbate (in cases where reputation provides governance) or mitigate (in cases where the no-mimic constraint provides governance) the enforcement problem.

We apply our analysis to offer some new perspectives on executive pay practices. First, our findings may shed some light on firms' choices regarding the mix of compensation instruments. Executives are commonly paid using a wide variety of instruments, including cash bonuses, stock, and stock options, and there has been little work by financial economists on determinants of firms' choices over these instruments. Our analysis identifies one way in which discretionary payments - that is, payments such as annual bonuses that are determined directly by the board of directors - differ from stock-based instruments: discretionary payments may convey information that is relevant for valuing the firm, while stock-based instruments do not. Second, our analysis offers new insight into potential effects of executive compensation disclosure rules. Firms required to disclose compensation amounts will do so keeping in mind the effects of such disclosures on the value of the firm. Our model therefore suggests that disclosure rules may affect how firms structure relationships with top managers. 


\section{First Benchmark Model: The Stage Game with Signaling}

We begin by considering a one-period model in which a firm's wage payments may convey information to market participants. A publicly traded firm hires an agent (the manager) to take effort. The firm's activity consists of a project that can either succeed or fail. If the project succeeds, the firm earns $\pi_{s}$, while if the project fails, the firm earns $\pi_{f}<\pi_{s}$. Let the probability of success, $p$, be a function of the manager's unobserved effort, $e$, and let $p(e)$ be continuously differentiable with $p(0)=0, p^{\prime}(e)>0$ and $p^{\prime \prime}(e)<0$.

We assume the firm is risk neutral, while the manager is risk and effort averse. Let the manager's utility function for wealth be denoted by $u(w)$, where $u$ is increasing and concave. We assume the manager has reservation utility $\bar{u}$. Let the manager's cost of effort be $c(e)$, where $c$ is continuously differentiable with $c^{\prime}(e)>0$ and $c^{\prime \prime}(e)>0$. A contract specifies a wage to be paid to the manager as a function of the outcome of the project. We write a contract as a pair $(s, b)$, where $s$ is a salary to be paid immediately after the contract is put in place and $b$ is a bonus paid in the event that the firm's project is successful.

\subsection{The Second-Best Incentive Contract}

We first establish properties of the second-best incentive contract when the outcome of the firm's project is observable to all parties (the firm, the manager, and stock market participants) simultaneously. We begin by analyzing the manager's choice of effort conditional on the contract selected. We assume the underlying structure of the problem is such that it is profitable for the firm to hire the manager and the firm is strictly better off if it induces the manager to take a positive level of effort. Since the manager's objective function is continuously differentiable and strictly concave in effort, his optimal effort choice, $e^{*}$, is characterized by the following first-order condition:

$$
p^{\prime}\left(e^{*}\right)(u(s+b)-u(s))=c^{\prime}\left(e^{*}\right)
$$

Using the implicit function theorem, we define $e^{*}(s, b)$ as the solution to (1). Note that effort is increasing in $b$ and decreasing in $s$.

Under the assumption the firm holds all the bargaining power in the relationship, the secondbest contract maximizes the firm's profits while satisfying the manager's individual rationality constraint with equality. We can therefore write the firm's problem as

$$
\max _{(s, b)} p\left(e^{*}(s, b)\right)\left(\pi_{s}-b\right)+\left(1-p\left(e^{*}(s, b)\right)\right) \pi_{f}-s
$$




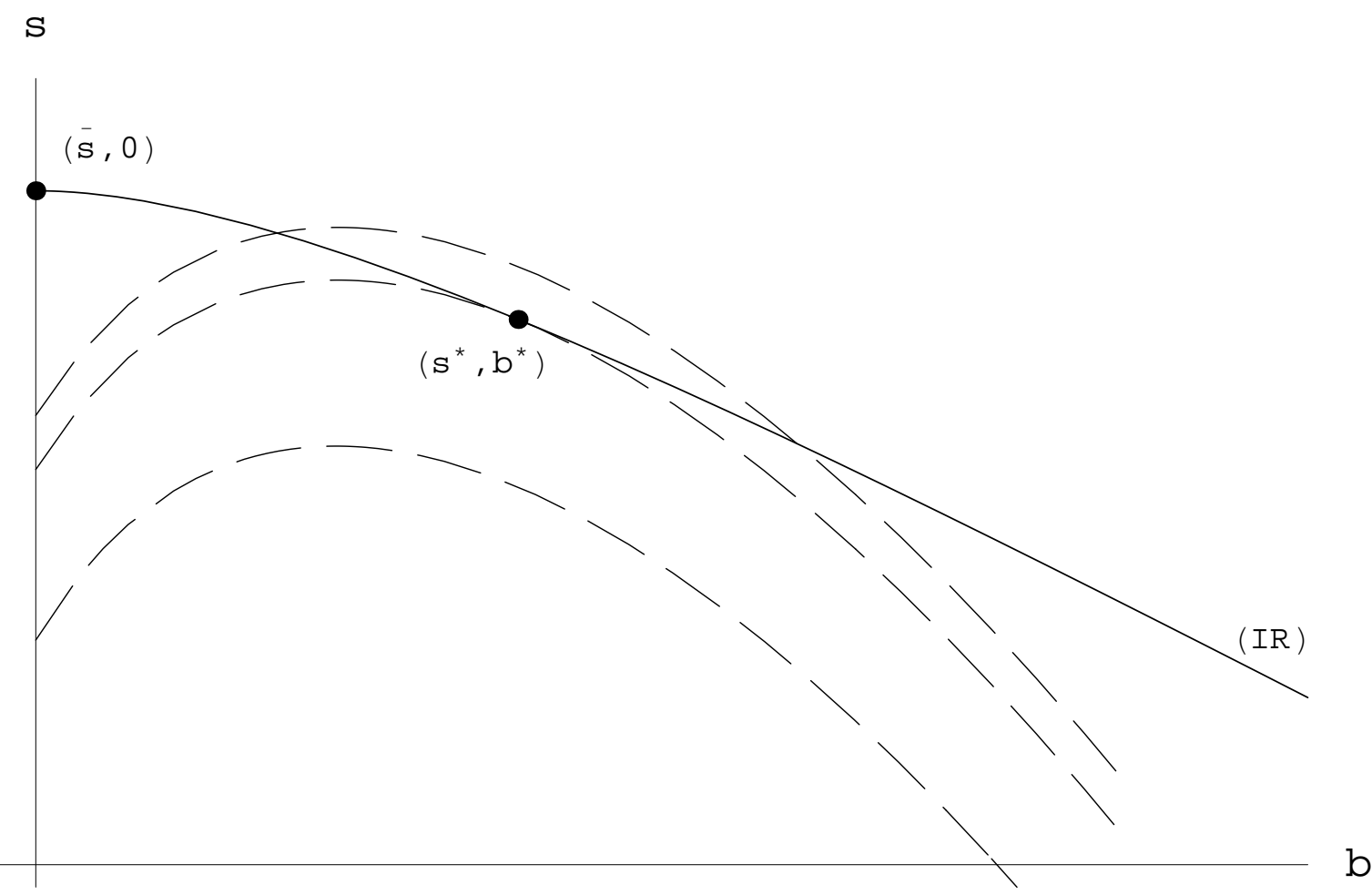

Figure 1: The second-best contract.

subject to

$$
p\left(e^{*}(s, b)\right) u(s+b)+\left(1-p\left(e^{*}(s, b)\right)\right) u(s)-c\left(e^{*}(s, b)\right)=\bar{u} .
$$

We represent the solution to this program graphically in Figure 1. Placing $b$ on the horizontal axis and $s$ on the vertical axis, we plot (with a solid line) the set of contracts that satisfy the manager's individual rationality constraint with equality. This curve begins at the full-insurance contract $(\bar{s}, 0)$, where $\bar{s}$ is defined by $u(\bar{s})=\bar{u}$. As $b$ increases, the manager takes more effort and is exposed to more risk. To compensate the manager for these costs, the expected level of pay must increase. Dashed lines in the figure are the firm's iso-profit curves. The point marked $\left(s^{*}, b^{*}\right)$ denotes the second-best contract; it is the point where an iso-profit curve is tangent to the manager's individual rationality constraint.

\subsection{Signaling with Perfect Governance}

We enrich this simple framework to explore properties of equilibrium incentive contracts when the parties to the contract observe the outcome of the project before market participants. 


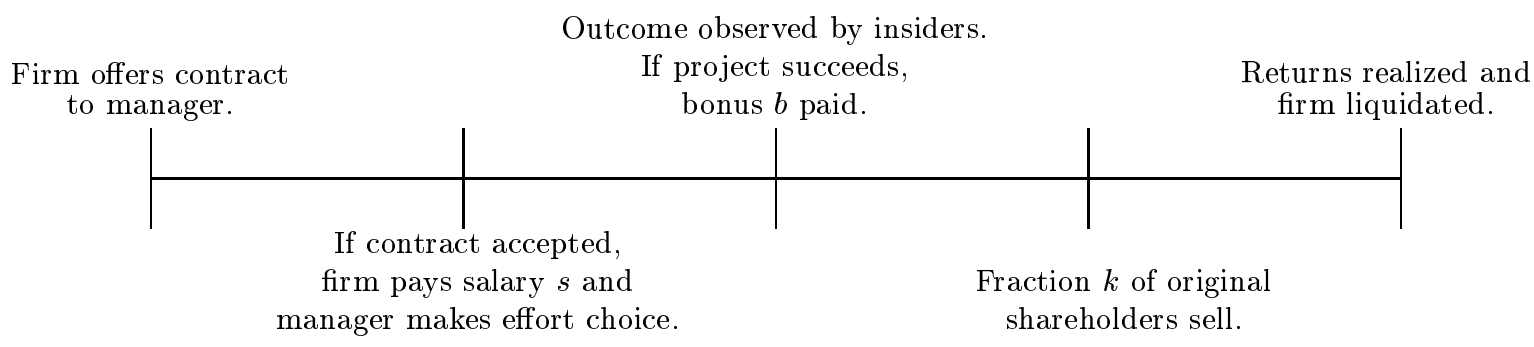

Figure 2: Timeline.

Here, we consider a case in which an (unmodeled) governance mechanism is sufficiently strong to ensure the second-best contract is always feasible. This allows us to focus attention on the effects of the firm's incentives to choose wage payments strategically.

Consider a single-period model with two types of shareholders. (See timeline in Figure 2.) It is common knowledge that fraction $k$ of the original shareholders must, for exogenous reasons, sell their shares prior to the final realization of the firm's cash flows. The remaining $1-k$ keep their shares until the end of the period. ${ }^{2}$ At the beginning of the period, the firm offers a contract to its manager. If the manager accepts the contract, he exerts unobservable effort. Immediately after the manager's effort choice, the project's outcome is revealed to both the firm and the manager. However, this information comes in the form of a signal that is not observed by outsiders. The firm then chooses what payments to make to the manager. ${ }^{3}$

While stock market participants cannot observe the signal received by the insiders, they can observe the bonus payment from the firm to the manager. Fraction $k$ of the original shareholders sell their shares at a price that is conditioned on the size of the bonus. After this first round

\footnotetext{
${ }^{2}$ While the specific assumption that the original shareholders have exogenously differing time horizons is common in the literature on signaling to financial markets (see Miller and Rock (1985)), it is not necessary for our results. We need only that the firm chooses its bonus payment to maximize a weighted sum of first- and second-round stock prices, with higher values of $k$ indicating higher weight on first-round prices. We make the differing time horizon assumption simply as a way of giving a literal interpretation to the firm's myopia. Other justifications for the assumption of corporate myopia have been suggested, and would work equally well here. For example, Stein (1988) studies a model in which a corporate raider arrives during the first round of trading with probability $k$. Shareholders wish the firm to have a high first-round stock price to prevent a potential raider from buying the firm's shares at a discount.

${ }^{3}$ In the U.S., actual compensation amounts for top managers are selected by a committee of the board. We abstract from any agency problems between the shareholders and the board, and assume that the firm simply chooses the bonus payment that maximizes the average payoff to the original shareholders.
} 
of trading, the project's outcome is publicly revealed. Shareholders then receive the difference between the project's payoff and the wage payments, and the game ends. ${ }^{4}$

Note that the payoff to the fraction $k$ of original shareholders who sell in the first round of trading depends on the market's assessment of the outcome of the firm's project. If the payment from the firm to the manager depends on the project outcome, then market participants will update their beliefs as to the firm's terminal value based on this payment. This raises the possibility that the firm may wish to alter its payments to the manager in order to affect the market's beliefs as to the project's outcome. ${ }^{5}$ In particular, a firm with an unsuccessful project may wish to pay the manager the bonus associated with success. Equilibrium, of course, requires that such attempts to fool the market must fail.

Within this framework, we examine how equilibrium contract offers are affected by the firm's desire to affect share prices in the first round of trading. Since equilibrium requires that attempts to fool the market must fail, wage contracts must satisfy a no-mimic constraint: the "low" types - the firms with failed projects - must not find it worthwhile to mimic the "high" types. The original shareholders of a firm with a failed project that elects to pay no bonus receive payoff

$$
\pi_{f}-s
$$

If, however, this firm elects to mimic a firm with a successful project, then the average payoff to the firm's original shareholders is

$$
k\left(\pi_{s}-s-b\right)+(1-k)\left(\pi_{f}-s-b\right) .
$$

Our no-mimic constraint is therefore given by

$$
b-k\left(\pi_{s}-\pi_{f}\right) \geq 0
$$

\footnotetext{
${ }^{4}$ We assume these terminal dividend payments are non-contractible. The assumption that the firm's terminal payoff is non-contractible is standard in literatures on both signaling to financial markets and managerial remuneration (see, for example, Holmstrom and Tirole (1993)).

${ }^{5}$ In our stylized model, "project outcome" is intended to represent any non-public information the firm uses to assess managerial performance. This could reflect information that the firm does not want to disclose (as in the case of a "competitively sensitive" performance measure) or information that the firm cannot credibly disclose (as may be the case for a "subjective evaluation" of performance). Firms convey information to markets in many ways, and our model does not require that all payoff-relevant information be transmitted through bonuses.
} 


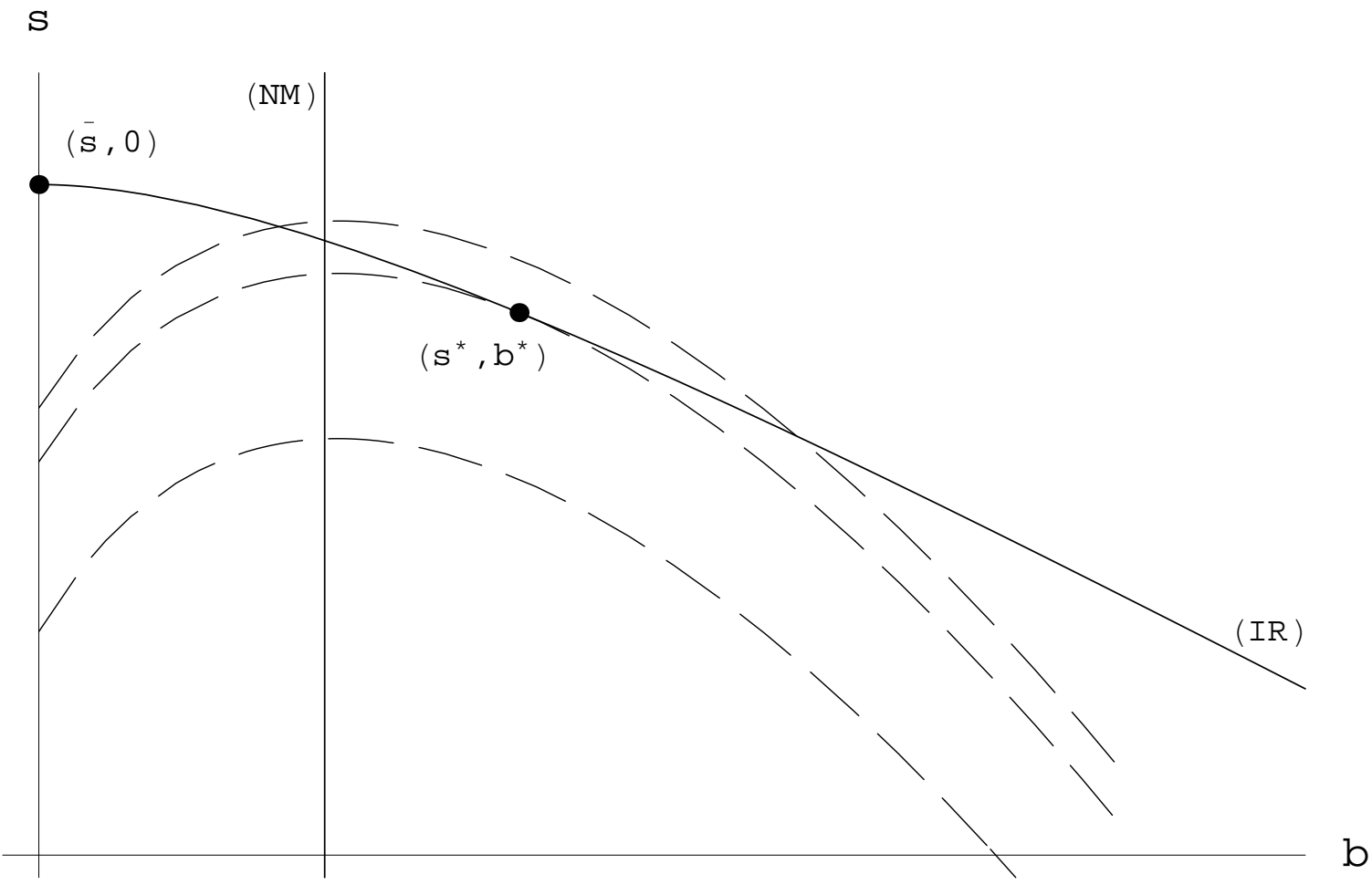

Figure 3: An efficient separating contract.

It is not profitable for an unsuccessful firm to attempt to mimic a successful firm if the bonus specified in the contract satisfies this constraint.

We use graphs similar to Figure 1 to identify types of equilibrium contracts and compare welfare under each. We identify three types of equilibrium contracts. Efficient separating contracts feature a one-to-one mapping from project outcomes to bonus payments and secondbest effort and risk sharing. Inefficient separating contracts have a one-to-one mapping from outcomes to bonuses, but induce higher effort and place more risk on the manager compared to the second-best contract. Pooling contracts have the property that wages do not depend on the project outcome; that is, no output-contingent bonuses are paid. In the text, we offer a graphical analysis to convey the main intuition for our results; a full characterization of this signaling game is contained in the appendix.

In Figure 3, we show a setting where $k$, the fraction of original shareholders who intend to sell during the first round of trading, is low. The diagram is identical to Figure 1, except that we have added the (NM) constraint as a solid line. This constraint requires that $b$ is sufficiently high so that firms with failed projects do not mimic firms with successful projects. Hence, 


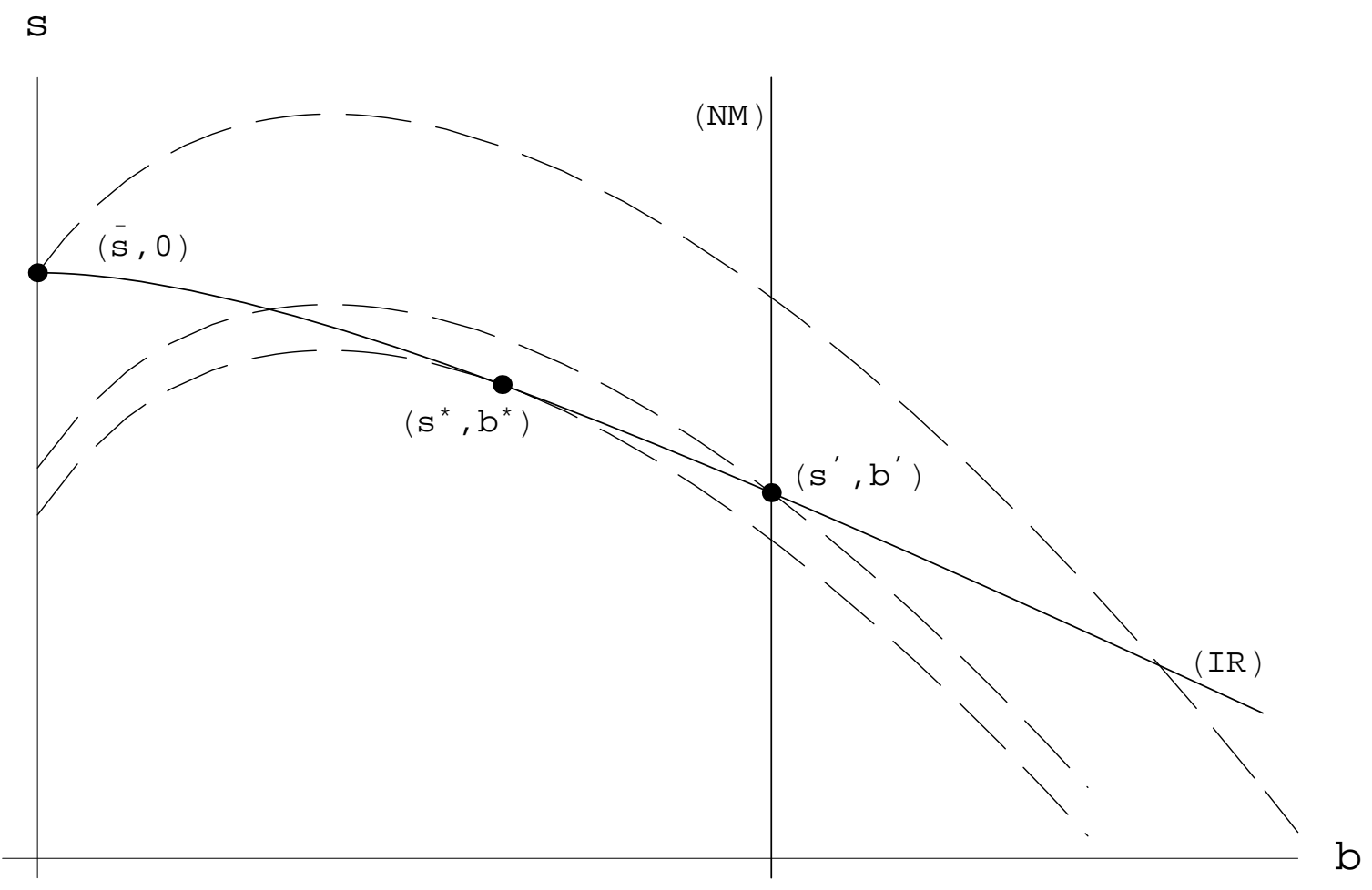

Figure 4: An inefficient separating contract.

all contracts to the right of the line satisfy this constraint. Since the second-best contract in Figure 3 satisfies the (NM) constraint, a firm offering this contract would find that it has no incentive to deviate from the terms of the contract after learning the project's outcome. A firm with a failed project finds it prohibitively expensive to attempt to mimic a successful firm, while a successful firm pays bonus $b^{*}$. Thus, for low values of $k$, the equilibrium features an efficient separating contract. In these cases, the manager's incentive constraint induces a larger bonus than is necessary to signal - the firm's myopia therefore does not affect the contracts offered to managers.

Figure 4 features a setting with a higher value of $k$. Since a higher fraction of original shareholders now wish to sell early, the temptation for firms with failed projects to mimic those with successful projects is greater. This means $b$ must be even higher to satisfy the no-mimic constraint. The (NM) line in Figure 4 is shifted to the right of that depicted in Figure 3. There are two candidates for the equilibrium contract here. First, consider the highest-profit contract that satisfies both the (NM) and (IR) constraints. This point is where the (NM) line intersects the manager's (IR) constraint and is denoted by $\left(s^{\prime}, b^{\prime}\right)$. A second possibility is that the firm 


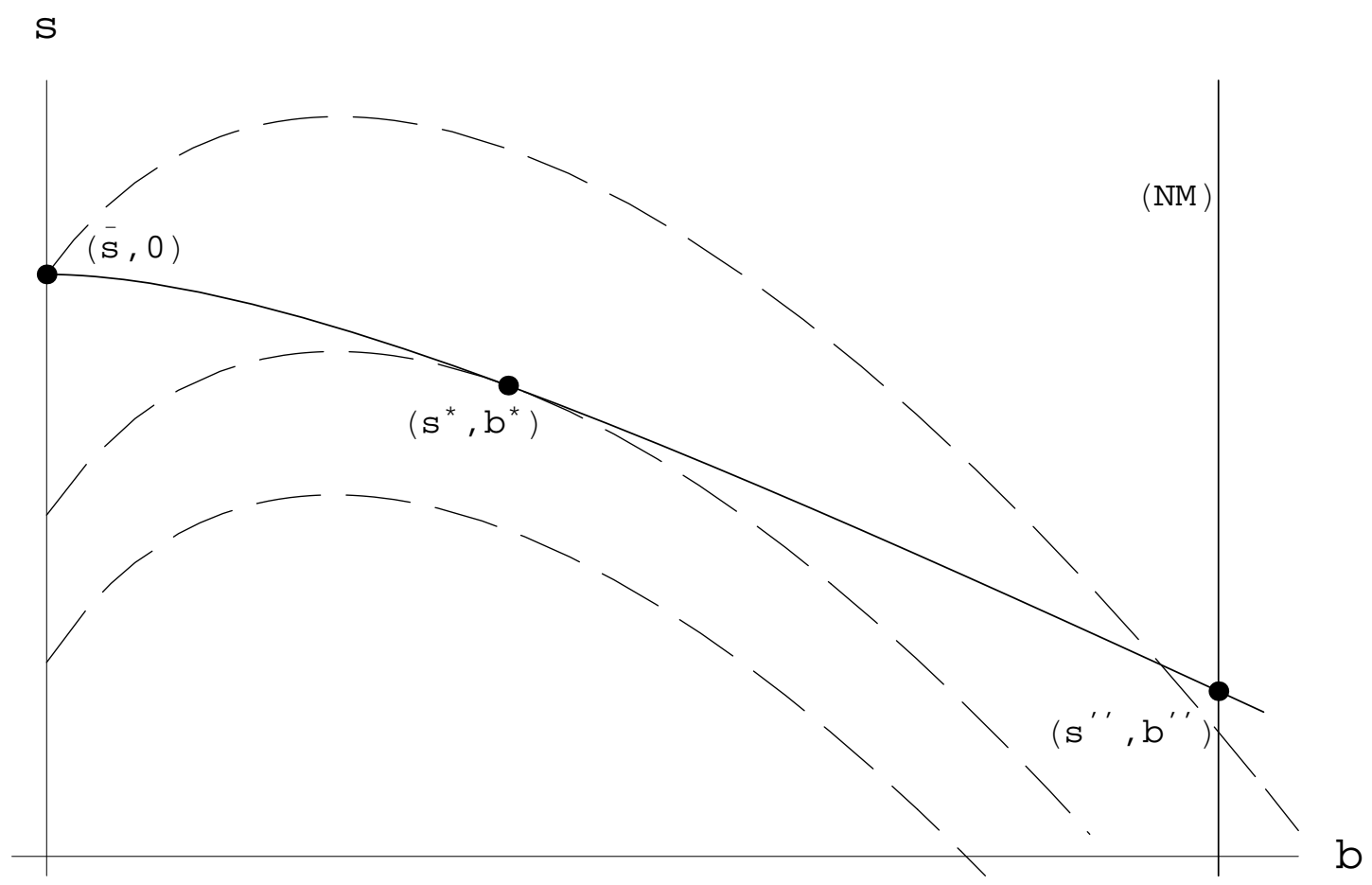

Figure 5: A pooling contract.

could choose to offer a contract that does not satisfy the (NM) constraint; among these, $(\bar{s}, 0)$ yields the highest profits. To see this, first note that no contract with $b>0$ that does not satisfy (NM) can be an equilibrium. Anticipating that the bonus would be paid even in the event of failure, the manager would exert zero effort and the project would never succeed. Given this, the firm is better off offering the full-insurance contract.

To determine which of these contracts will be offered, we examine the iso-profit lines in Figure 4. Iso-profit lines that are higher on the figure mean lower profits, so the firm prefers $\left(s^{\prime}, b^{\prime}\right)$ to $(\bar{s}, 0)$. For this value of $k$, the manager's incentive constraint does not induce a sufficiently large bonus to permit firms with successful projects to identify themselves. Hence, firms must offer a contract featuring a larger bonus than in the second best. As this equilibrium contract departs from second-best effort provision and risk sharing but still permits identification of firms with successful projects, we refer to it as an inefficient separating contract.

Next, consider an even higher value of $k$, as shown in Figure 5. In this figure, the profitmaximizing separating contract, which is denoted by $\left(s^{\prime \prime}, b^{\prime \prime}\right)$, is on a lower iso-profit curve than the full-insurance contract. Since a very high fraction of the firm's original shareholders plan to 
sell at the first round of trading, the temptation for firms with failed projects to try to mimic firms with successful projects is great. Offering a contract that permits a successful firm to distinguish itself is costly because such a contract places excessive effort incentives and risk on the manager. For this value of $k$, these costs are so great that the firm is not willing to offer such a contract; rather, the firm offers a full-insurance, pooling contract. ${ }^{6}$

The welfare implications of this model are particularly easy to study. In all equilibria, the manager receives his reservation utility and the market's valuations of the firm are correct. Hence, the welfares of the manager and the market participants do not vary as the equilibrium changes. The firm's iso-profit lines are therefore identical to iso-welfare lines. From the above discussion, it is clear that profits are monotonically decreasing in $k$. When the firm is more myopic (in the sense that a larger fraction of original shareholders intend to sell during the first round of trading), the firm makes the manager's pay more sensitive to performance in order to permit signaling. Since the manager must be compensated for bearing additional risk and effort costs, the firm's expected wage bill increases, leading to lower ex ante expected profits.

Finally, we note that our main intuition here is robust to consideration of a continuous outcome space for the firm's project. For example, we can extend our model in a manner similar to the Miller and Rock (1985) analysis. A firm with a fixed stock of capital hires a manager whose hidden effort increases the rate of return on the firm's project. The firm invests its entire stock of capital, net of wages, in the project. Wage payments are then publicly observed, followed by a round of trading. Proceeds from the investment are distributed. The nomimic constraint in this model is a differential equation specifying how steep the wage contract must be in order to prevent firms with low-return projects from attempting to manipulate the market's beliefs. Increases in $k$ raise the slope of the no-mimic constraint, and can cause the firm to shift away from the second-best contract toward a contract that imposes higher effort and risk costs on the manager than the second-best. Even simple cases of this model are difficult to solve analytically, however, since the no-mimic constraint may bind over only part of the range of possible project outcomes.

\footnotetext{
${ }^{6}$ This statement presumes the firm's profits are positive when it offers the full-insurance contract. If this contract yields negative expected profits, then the firm shuts down when $k$ is large.
} 


\section{Second Benchmark Model: Relational Incentive Contracts without Signaling}

The premise of the analysis thus far is that bonus payments to managers can be based on information that is not held by those outside the firm. Given this, it is natural to ask how such contracts are to be governed. Since non-public information is inherently non-verifiable, such contracts cannot be enforced by external third parties. ${ }^{7}$ Hence, we briefly consider a model in which the firm has no incentive to boost short-term share prices, but must rely on a reputational mechanism (which we model in a repeated-game framework) to enforce its contract offer. Our analysis here is very similar to a benchmark case studied by Baker et al. (1994), who expand on this benchmark by considering how the presence and quality of a verifiable performance measure affect the firm's ability to use a subjective measure of performance as part of a relational contract. In the next section, we combine the signaling and reputation models to study how the firm's incentive to choose wage payments strategically affects the efficacy of reputation as a contract enforcement mechanism.

Several modeling difficulties immediately arise when moving from the stage game studied above to the supergame-theoretic framework considered here. First, supergame models commonly have many equilibria, which means that definitive predictions as to outcomes are not feasible. Second, the folk theorem suggests that as long as the future is sufficiently important to the players, any individually rational payoffs can be supported as an equilibrium. We address these difficulties in a manner similar to Baker et al. (1994), by assuming that the firm's discount factor is strictly less than one, and by focusing on the set of equilibria that can be supported using "trigger strategies" in which players agree to trust each other as long as neither player has violated that trust in the past. Such strategies have the virtue of being easy to analyze, but ignore issues relating to optimal punishments and renegotiation. ${ }^{8}$

\footnotetext{
${ }^{7}$ This statement requires some qualification. It is possible that information that is non-public at date $t$ may become public and verifiable at date $t+1$. A firm could write a contract with a manager specifying a payment to be made at date $t$, with enforcement provided by recourse to the courts at date $t+1$. In this case, the analysis of Section 2 still applies. We argue, however, that many aspects of managerial performance are non-verifiable, and hence that explicit consideration of reputational governance is necessary for understanding use of non-public information in firms.

${ }^{8} \mathrm{~A}$ more thorough discussion of these issues is offered by Baker et al. (1994). Levin (1998) shows that trigger strategies are renegotiation-proof and optimal punishments in a model of relational incentive contracts with a single non-verifiable performance measure. His analysis, however, allows for contingent payments from the agent
} 
We embed the stage game introduced in the previous section in a repeated-game framework. In each period, the firm offers the manager a contract $(s, b)$ and the manager decides whether to accept employment. If the contract is accepted, the firm pays salary $s$ and the manager selects an effort level $e$. The firm and the manager then observe the project outcome and the firm chooses what bonus (if any) to pay. Outsiders then observe the bonus payment from the firm to the manager. To eliminate the firm's incentive to act myopically, we assume that all shareholders intend to hold their shares until the end of the stage game. ${ }^{9}$ Finally, project outcomes are revealed, profits from the current period's project are paid as dividends, and the original shareholders may sell their shares. ${ }^{10}$ This stage game is repeated infinitely, with the parties discounting the future at rate $\delta=1 /(1+r)<1$.

We assume that if the firm deviates from the terms of the contract, the manager alters his behavior in all subsequent periods according to a trigger strategy. If the firm reneges on its promise to pay bonus $b$ if the project succeeds, then the manager punishes the firm by refusing to trust the firm's contract offers in all subsequent periods. Since, in this case, there is no alternative to reputation as a governance mechanism, the best the firm can do in the periods after it reneges is either to offer the full-insurance contract or shut down. We assume here that if the firm offers a contract with $b>0$ and reneges by paying no bonus when the project has succeeded, then market participants observe this breach prior to the round of trading.

To study this model, we first introduce some notation. Denote by $V(b)$ the maximized value of the firm's net cash flows in the current period if the firm can credibly commit to paying a bonus $b$ for project success. Since profit maximization implies the manager's incentive and individual rationality constraints will bind, a given $b$ implies unique choices of salary $s$ and effort $e$. Denote these salary and effort levels as a function of $b$ by $s(b)$ and $e(b)$. We write $V$ as

$$
V(b)=p(e(b))\left(\pi_{s}-b\right)+(1-p(e(b))) \pi_{f}-s(b)
$$

Under the assumptions on the functions $p(e), c(e)$ and $u(w)$ made in the previous section, it is the case that $V$ is differentiable and strictly concave.

Suppose the firm offers a contract $(s, b)$ and then observes project success. If the firm reto the principal. As "negative bonuses" appear not to be present in the managerial compensation context, we do not consider this possibility.

${ }^{9}$ In Section 4 below, we allow fraction $k$ of firm's original shareholders to sell their shares immediately after outsiders observe the bonus payment from the firm to the manager. Here, we assume $k=0$.

${ }^{10}$ We retain the assumption that these dividends are not contractible. 
neges on its contract, it keeps the current period's bonus payment $b$. However, the manager then punishes the firm in all subsequent periods by refusing to trust the firm's promise to pay performance-based bonuses. Since, in this event, there are no alternative contractual enforcement mechanisms, the firm's two choices are to offer a full-insurance contract in subsequent periods and earn profits $V(0)$ or to shut down, earning zero profits. If the firm chooses to pay the bonus, then the net present value of its profits is given by

$$
\pi_{s}-b+\sum_{\tau=1}^{\infty} \delta^{\tau} V(b)=\pi_{s}-b+\frac{1}{r} V(b) .
$$

If the firm does not pay the bonus, its profits are

$$
\pi_{s}+\frac{1}{r} \max [0, V(0)]
$$

Our reputational governance constraint is therefore given by

$$
V(b)-\max [0, V(0)] \geq r b
$$

The firm chooses to pays the bonus $b$ only if it is smaller than the value of the firm's reputation. Hence, the largest $b$ solving (RG) with equality is the largest bonus that the manager is willing to trust the firm to pay. If the firm offers a larger bonus, the manager will expect the firm to renege on its promise and will exert no effort, expecting no bonus to be paid. Note that, in general, there exists a continuum of bonuses smaller than the largest solving (RG) with equality that are also equilibria; as in most supergame-theoretic models, we are able to identify only a range of possible equilibria. Note also that if the second-best bonus does not satisfy (RG), then the largest bonus that satisfies (RG) with equality is the pareto-best equilibrium.

Figure 6 provides a graphical illustration. We assume $V(0)<0$ and plot $b$ on the horizontal axis. The largest credible bonus is the largest $b$ where the $V(b)$ and $r b$ curves intersect. For $r=.1$, the firm can achieve the second-best bonus, $b^{*}$, but as $r$ increases the largest credible bonus falls. For $r$ sufficiently large $(r=.3$, in the figure), no bonus offer is credible. The figure makes clear that the inefficiency here is related to the rate at which the firm discounts future cash flows. If the future is sufficiently important, then the second best can be reached. However, as the firm's discount rate falls, the temptation to renege on the second-best bonus payment is too great for this contract offer to be credible. We refer to this source of inefficiency as "impatience," and argue that this is distinct from the "myopia" that led to departures from the second-best in the previous section. In our model, a myopic firm (that is, one with a high value of $k$ ) takes actions intended to boost short-run share prices by conveying information 


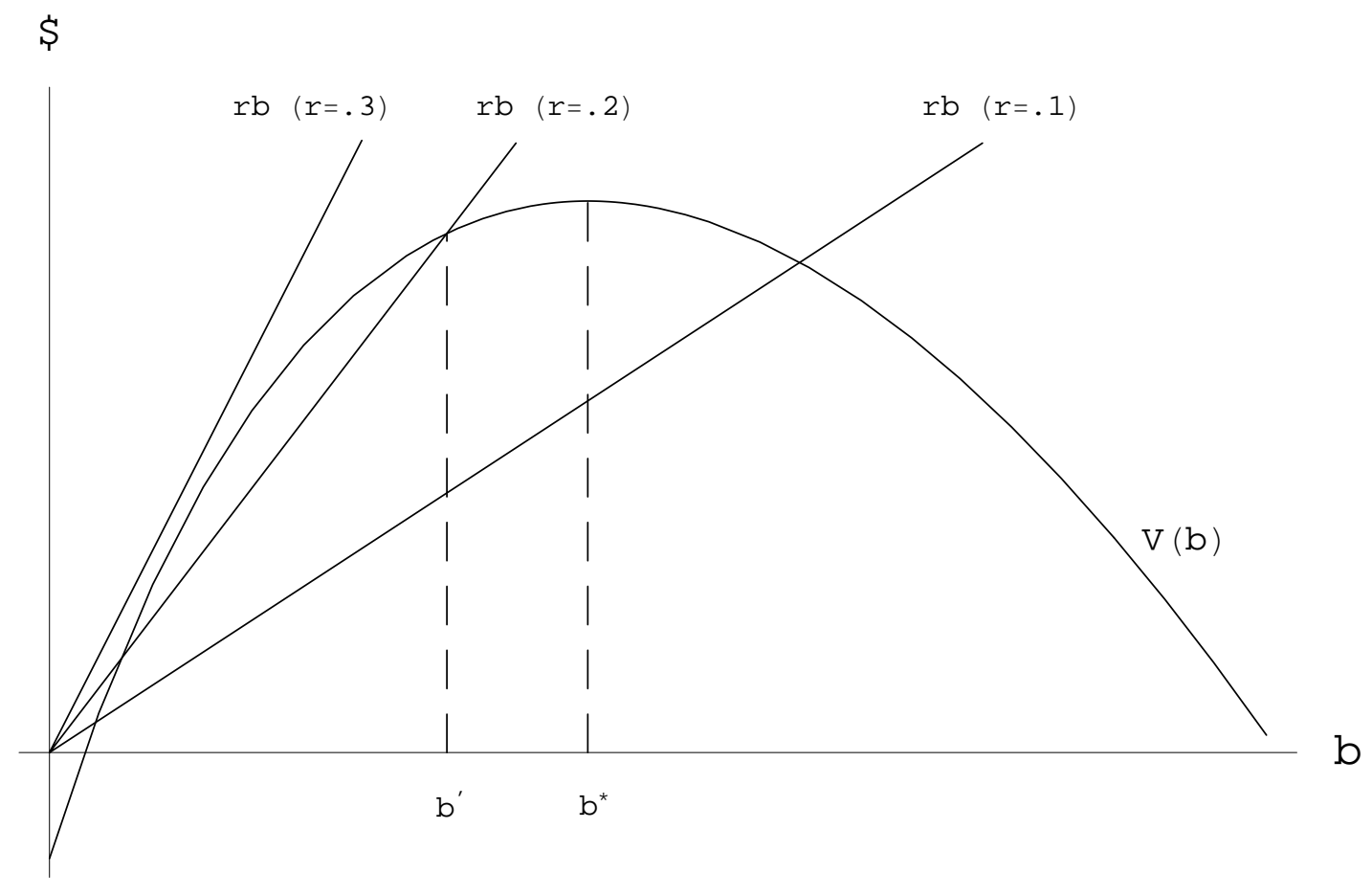

Figure 6: The largest credible bonus shifts downward as $r$ increases.

about future cash flows without changing the timing of those cash flows. An impatient firm (one with a low $\delta$ ) takes actions to shift the actual timing of cash flows from the future into the present. ${ }^{11}$ In the next section, we consider how the firm's incentives for myopic behavior can either exacerbate or mitigate inefficiencies arising from impatience.

\section{Signaling and Relational Incentive Contracts}

We now combine the analyses of the previous two sections to study how the firm's relationship with its manager is affected by its incentive to choose wage payments strategically. Our model yields a non-monotonic relationship between the degree of the firm's myopia and the bonuses the firm can credibly offer the manager. If reputation-based bonuses are feasible, then increases in

\footnotetext{
${ }^{11}$ We give myopia a literal interpretation by assuming the firm prefers a high short-run share price to meet liquidity needs of its shareholders, but (as discussed in footnote 2) other justifications for corporate myopia have been suggested. Impatience presumably relates to the the interest rate at which the firm can borrow and lend, and we therefore argue that there is no necessary relationship between a firm's degrees of impatience and myopia.
} 
myopia may hamper the use of such contracts (and reduce the largest feasible bonus payment) by making the fallback contracting environment more attractive. If reputation-based bonuses are not feasible, then increases in myopia may lead to larger bonuses.

Our model here is identical to that of the previous section, except that we stipulate that fraction $k$ of original shareholders intend to sell their shares just prior to the public revelation of the project outcome. As above, each period the firm first offers the manager a contract $(s, b)$ and the manager decides whether to accept or reject. If the contract is accepted, the firm pays salary $s$ and the manager selects an effort level $e$. Insiders then observe the project outcome and the firm chooses what bonus (if any) to pay. Outsiders then observe the bonus payment from the firm to the manager, and fraction $k$ of the original shareholders sell.

We assume that if the firm reneges on its contract offer by paying no bonus when the project has succeeded, then market participants observe this breach immediately - that is, prior to the round of trading in which fraction $k$ of original shareholders sell. This is a strong assumption, and we justify it by arguing that we are interested in examining conditions favorable to the use of reputation as a contractual enforcement mechanism. Note that if market participants receive later notification (say, just after the round of trading where fraction $k$ of original shareholders sell), then this provides a stronger incentive for the firm to renege and reduces the efficacy of reputation. ${ }^{12}$ Project outcomes are then revealed and profits from the current period's project are paid as dividends. This stage game is repeated infinitely, with discount rate $\delta$.

We assume that if the firm deviates from the terms of the implicit contract, the manager alters his behavior in all subsequent periods according to a trigger strategy. Here, the firm's deviations can take two forms: first, as noted above, the firm may elect to pay no bonus when the project has succeeded, and second, the firm may pay a bonus when the project has failed. In the first case, we assume that if the firm reneges on its agreement to pay bonus $b$ if the project is successful, then the manager punishes the firm by refusing to trust the firm's relational contract offers in all subsequent periods. In subsequent periods, the best the parties can do is to rely on contractual enforcement mechanisms other than reputation. ${ }^{13}$ An alternative governance

\footnotetext{
${ }^{12}$ Results similar to the ones we present below can also be derived under the assumption that market participants observe a breach just after the first round of trading. Note that in order to make reputation-backed contracts at all feasible, we must assume that market participants observe a breach at some point. Otherwise, the market value of the firm would never fall as a result of the breach.

${ }^{13}$ Baker et al. (1994) apply a similar assumption. In their model, if a firm reneges on a promise to pay a bonus based on a subjective evaluation of the employee's performance, then future contracts are based only on
} 
mechanism is provided here by the successful firm's incentive to pay a sufficiently large bonus to distinguish itself from a firm with a failed project. If, instead, the firm deviates from the agreement by paying the manager a bonus after the project has failed, we again assume the manager changes his behavior in all subsequent periods. In this case, the manager assumes that there is no relationship between project outcomes and bonus payments, so he exerts zero effort in all subsequent periods. ${ }^{14}$

We structure the analysis of this section by considering how each side of the reputational governance constraint in (RG) is affected by the firm's myopia. We focus first on how increases in $k$ impact the parties' fallback position. Then, we ask how the gains from reneging vary with $k$. This allows us to characterize the relationship between $k$ and the largest feasible bonus.

\subsection{The Fallback Position}

We begin by examining the contracting environment faced by the parties in the event that reputational governance is infeasible. The key insight is that even after breaching a relational contract, a firm with a successful project still wants to distinguish itself from a firm with a failed project. Hence, we derive the associated no-mimic constraint. Let $b$ be the largest bonus that a firm can credibly offer when using the no-mimic constraint to enforce the contract. If a firm with a failed project pays no bonus, then the net present value of its profits is

$$
\pi_{f}+\frac{1}{r} V(b)
$$

Suppose, on the other hand, a firm with a failed project pays $b$ in an attempt to mimic a firm with a successful project. When the firm makes a non-zero bonus payment for a failed project, it forfeits its credibility in paying zero bonus for failed projects in the future. The manager's trigger strategy, as described above, stipulates that all future bonus offers will be ignored, so the best the firm can do in the future is to offer the full-insurance contract or shut down, earning profits $(1 / r) \max [0, V(0)]$. The fraction $k$ of shareholders who sell at the first round of trading receive payoff $\pi_{s}-b+(1 / r) V(b)$, since the market believes a firm paying $b$ has a successful current project and expects to earn profits of $V(b)$ in all future periods. The actual outcome of the firm's project then becomes known publicly prior to the end of the period. Hence, the fraction $1-k$ of shareholders who do not sell receive payoff $\pi_{f}-b+(1 / r) \max [0, V(0)]$, since the

\footnotetext{
verifiable measures of performance.

${ }^{14}$ Our main findings are robust to changes in this assumption; we obtain similar results if the manager does not change his future behavior when the firm pays a bonus following project failure.
} 
market knows the firm will be unable to make credible bonus offers in the future. The average payoff to original shareholders is

$$
k\left(\pi_{s}-b+\frac{1}{r} V(b)\right)+(1-k)\left(\pi_{f}-b+\frac{1}{r} \max [0, V(0)]\right) .
$$

Since, in equilibrium, attempts to fool the market must be unprofitable, we combine (2) and (3) to obtain a new no-mimic constraint:

$$
b \geq k\left(\pi_{s}-\pi_{f}\right)-\frac{1-k}{r}(V(b)-\max [0, V(0)]) .
$$

The bonus that allows a firm with a successful project to distinguish itself from a firm with a failed project is the smallest solution to this inequality.

We use this no-mimic constraint to characterize the bonus offers that are credible in the fallback position. To do this, we first define $b^{f b}(k)$ as the largest bonus offer the firm can make when relational governance is not used to enforce the contract. If $V(0)<0$ and $k$ is small, then it is possible that the largest bonus made credible by the no-mimic constraint is too small to result in positive profits for the firm. This occurs if $k<k_{0}=b_{0} /\left(\pi_{s}-\pi_{f}\right)$, where $b_{0}$ is defined implicitly as the smallest solution to $V(b)=0$. In this case, the firm prefers to shut down rather than offer the contract featuring the bonus made feasible by $\left(\mathrm{NM}^{\prime}\right)$. For $V(0)<0$ and $k \in\left[0, k_{0}\right)$, there is no feasible contract featuring a positive bonus in the event that the relational contract is breached, so we have $b^{f b}(k)=0$ in this region. Alternatively, if $k$ is very large, then it is possible that the bonus made credible by the no-mimic constraint is too large to result in positive profits for the firm. This occurs if the solution to $\left(\mathrm{NM}^{\prime}\right)$ is greater than the largest $b$ solving $V(b)=\max [0, V(0)]$. In the appendix, we show that there exists a $k_{2} \leq 1$ such that if $k>k_{2}$, then the smallest bonus that allows a successful firm to identify itself is so large that the firm prefers to offer the pooling contract $(\bar{s}, 0)$ (which yields profits $V(0)$ ), or shut down (if $V(0)<0$ ). We therefore have $b^{f b}(k)=0$ in this region.

For intermediate values of $k$, the bonus offer made credible by the no-mimic constraint does result in non-negative profits for the firm. In the event that the relational contract is breached, the firm can credibly offer the smallest bonus that satisfies $\left(\mathrm{NM}^{\prime}\right.$ ). Hence, if $k \in\left[k_{0}, k_{2}\right]$ (where $k_{0}$ is defined to be zero if $\left.V(0) \geq 0\right), b^{f b}(k)$ is given by the smallest solution to $\left(\mathrm{NM}^{\prime}\right)$. Note that $b^{f b}(k)$ is strictly increasing in $k$ over this interval. Since $V(b)-\max [0, V(0)]>0$ for $k \in\left[k_{0}, k_{2}\right]$, the right-hand side of $\left(\mathrm{NM}^{\prime}\right)$ is strictly increasing in $k$. Increases in $k$ shift the right-hand side upward, which means that $b$ must increase to preserve the inequality. ${ }^{15}$

\footnotetext{
${ }^{15}$ In the appendix, we prove the claim that $b^{f b}(k)$ is strictly increasing in $k$ when $k \in\left[k_{0}, k_{2}\right]$.
} 
To summarize the intuition for this characterization of $b^{f b}(k)$, we have that if $V(0)<0$ and $k$ is small, then the bonuses made credible by the no-mimic constraint are too small to result in positive profits. The firm is therefore unable to make any credible bonus offer in the event that the relational contract is breached, so $b^{f b}(k)=0$. For larger values of $k$, the no-mimic bonuses are large enough to yield positive profits, which allows the firm to credibly commit to the a positive bonus if the relational contract is breached. The function $b^{f b}(k)$ increases with $k$ on this region. For very large $k$, the no-mimic bonuses may be too large to result in positive profits, so again $b^{f b}(k)=0$. We use this fallback position to determine the value of the firm's reputation: if $b$ is the bonus that can be sustained using reputational governance, then the value to the firm of its reputation is

$$
\frac{1}{r}\left(V(b)-\max \left[0, V\left(b^{f b}(k)\right)\right]\right) .
$$

\subsection{The Gains from Reneging}

Next, we consider how a firm's incentive to signal may affect the gains to reneging on a relational contract. To quantify these gains, we first need to ask what payment a firm would make to the manager in the event that it elects to renege. Recall from Section 3 that when $k=0$, a firm that reneges simply withholds the entire bonus payment. When $k>0$, however, a firm with a successful project that reneges on a relational contract may still be willing to pay the manager enough to distinguish itself from a firm with a failed project. Thus, in order to understand the gains to reneging, we first need to specify the market's beliefs as to the outcome of the firm's current-period project conditional on observing an out-of-equilibrium bonus payment. Since reneging is off the equilibrium path, the market's beliefs as to the success of the firm's current project after observing a payment other than the equilibrium bonus or zero are not tied down by Bayes' Rule. In the appendix, we argue that application of the Cho and Kreps (1987) Intuitive Criterion yields a unique set of "reasonable" beliefs for the market to hold after observing an off-equilibrium-path bonus payment. However, to fully demonstrate the range of conditions under which our main findings hold, we consider a variety of beliefs that we argue may be reasonable for the market to hold.

Hence, in specifying the gains from reneging to derive our new reputational governance constraint, we allow for arbitrary beliefs; we let $b^{\text {rn }}$ denote the smallest bonus a successful firm can pay to the manager and still distinguish itself from a firm with a failed project. In 4.2.1 and 4.2.2 below, we consider specific instances of $b^{r n}$ and characterize the set of equilibria given 
these beliefs. As long as $b^{r n}<k\left(\pi_{s}-\pi_{f}\right)$, a firm that reneges on its relational contract will pay its manager bonus $b^{r n}{ }^{16}$ The gains to the firm from reneging are therefore given by

$$
b-b^{r n}
$$

where $b$ is, as above, the bonus that can be sustained using reputational governance. Combining (4) and (5), we obtain the following reputational governance constraint:

$$
V(b)-\max \left[0, V\left(b^{f b}(k)\right)\right] \geq r\left(b-b^{r n}\right) .
$$

The largest bonus that can be credibly offered using reputational governance is the largest $b$ satisfying $\left(\mathrm{RG}^{\prime}\right)$ with equality.

\subsubsection{Case 1: $b^{r n}$ is constant}

We first consider the case where $b^{r n}$ does not vary with $k$. We assume the market assesses the probability that the firm's current project is successful to be one as long as some bonus greater than or equal to $b^{r n}$ is paid, and that $b^{r n}$ does not vary with $k$. Given these market beliefs, a firm that chooses to renege on its relational contract will rationally pay a bonus of $b^{r n}$. The reputational governance constraint in this case is given by

$$
V(b)-\max \left[0, V\left(b^{f b}(k)\right)\right] \geq r\left(b-b^{r n}\right)
$$

In the appendix, we show that if $b^{r n}>0$, then there exists an equilibrium that fails the Cho and Kreps (1987) Intuitive Criterion. Therefore, the only beliefs that do not generate an equilibrium failing this criterion assess probability one to project success conditional on observing any $b>0$, and probability zero to success otherwise. Given these beliefs, a firm with a successful project that elects to renege on a promised bonus payment would rationally make a small, positive payment in order to distinguish itself from a firm with a failed project. Our analysis in this section covers the case of $b^{r n}=\epsilon$ as a special case.

We now characterize how the largest credible bonus under reputation varies with $k$. As in Section 2, we make use of graphical arguments in the text and present propositions in the appendix. Suppose first that $V(0)<0$ and let $k<k_{0}$. In this case, $b^{f b}(k)=0$, which implies

\footnotetext{
${ }^{16}$ The quantity $k\left(\pi_{s}-\pi_{f}\right)$ is the gain to the firm in the current period from convincing the market that its project is successful. Hence, if $b^{r n}>k\left(\pi_{s}-\pi_{f}\right)$, a firm that reneges on its relational contract would not find it worthwhile to attempt to convince the market that its current project is successful, and would pay bonus zero rather than $b^{r n}$.
} 


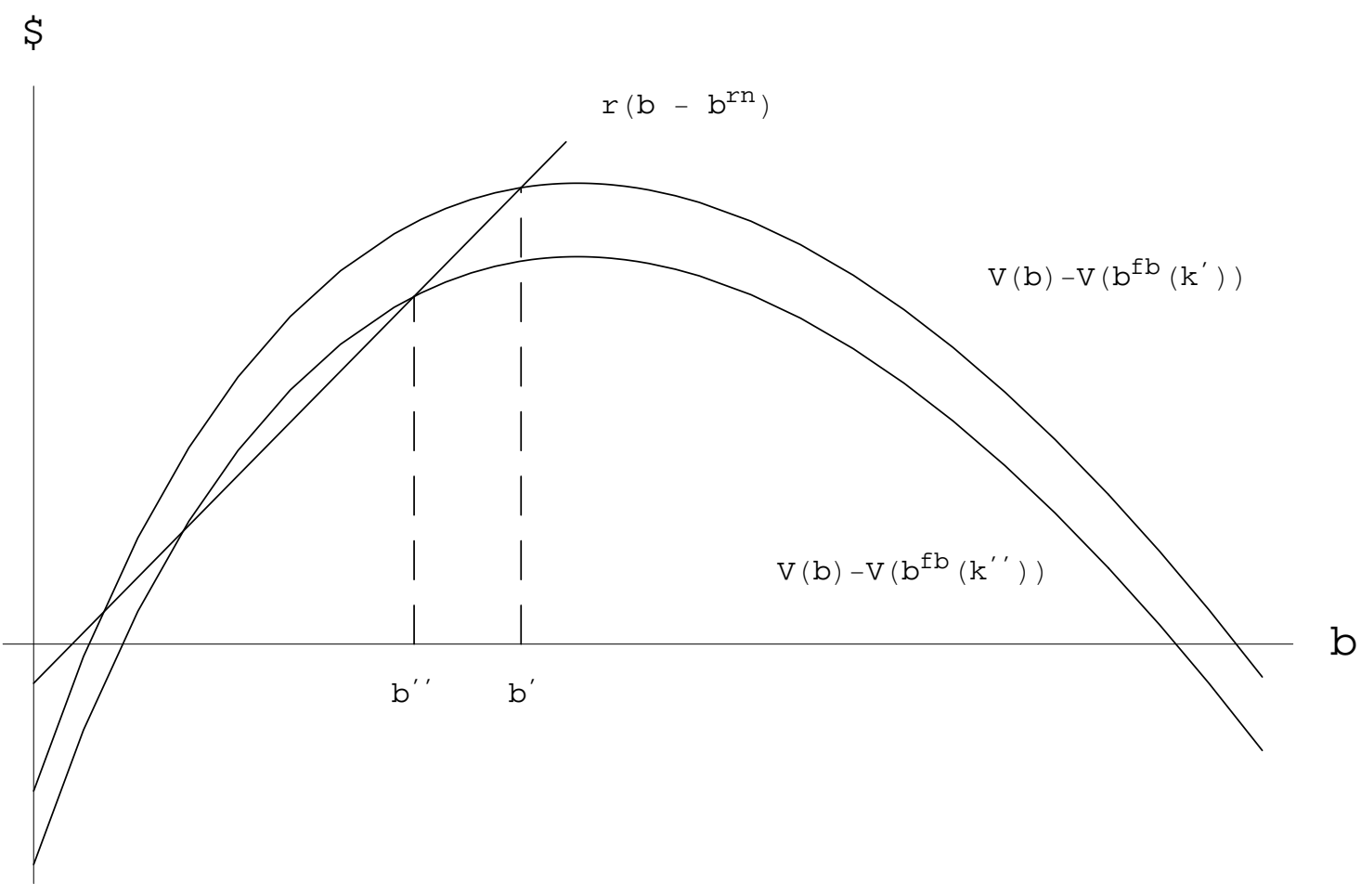

Figure 7: An increase in $k$ from $k^{\prime}$ to $k^{\prime \prime}$ causes the largest credible bonus to decrease from $b^{\prime}$ to $b^{\prime \prime}$.

that the fallback position in the event that the relational contract is ruptured is for the firm to shut down. Hence, over this region of $k$, the constraint in $\left(\mathrm{RG}^{\prime \prime}\right)$ reduces to that derived for the benchmark case (RG). This implies that the largest credible bonus under reputational governance does not vary with $k$ when $k \in\left[0, k_{0}\right)$.

Next suppose that $k_{0} \leq k \leq k_{2}$. Under these conditions, the no-mimic constraint allows the firm to commit to paying bonus $b^{f b}(k)$ in the fallback position. To see how the reputation-backed bonus varies with $k$ in this situation, we plot both sides of $\left(\mathrm{RG}^{\prime \prime}\right)$ in Figure 7 as $k$ increases from $k^{\prime}$ to $k^{\prime \prime}$. Note that as $k$ increases, the improvement in the fallback position causes the value of the firm's reputation to fall. Hence, the firm is more tempted to renege on a relational contract, and the largest credible bonus offer shifts downward from $b^{\prime}$ to $b^{\prime \prime}$. The largest reputation-backed bonus decreases with $k$ on an interval of $k$ that is bounded below by $k_{0}$.

Note that as $k$ continues to increase, the curve $V(b)-V\left(b^{f b}(k)\right)$ may eventually fall to the point where it is tangent to the line $r\left(b-b^{r n}\right)$. As depicted in Figure 8, further increases in $k$ cause the curve $V(b)-V\left(b^{f b}(k)\right)$ to fall below the $r\left(b-b^{r n}\right)$ line. In this case, the value of the 


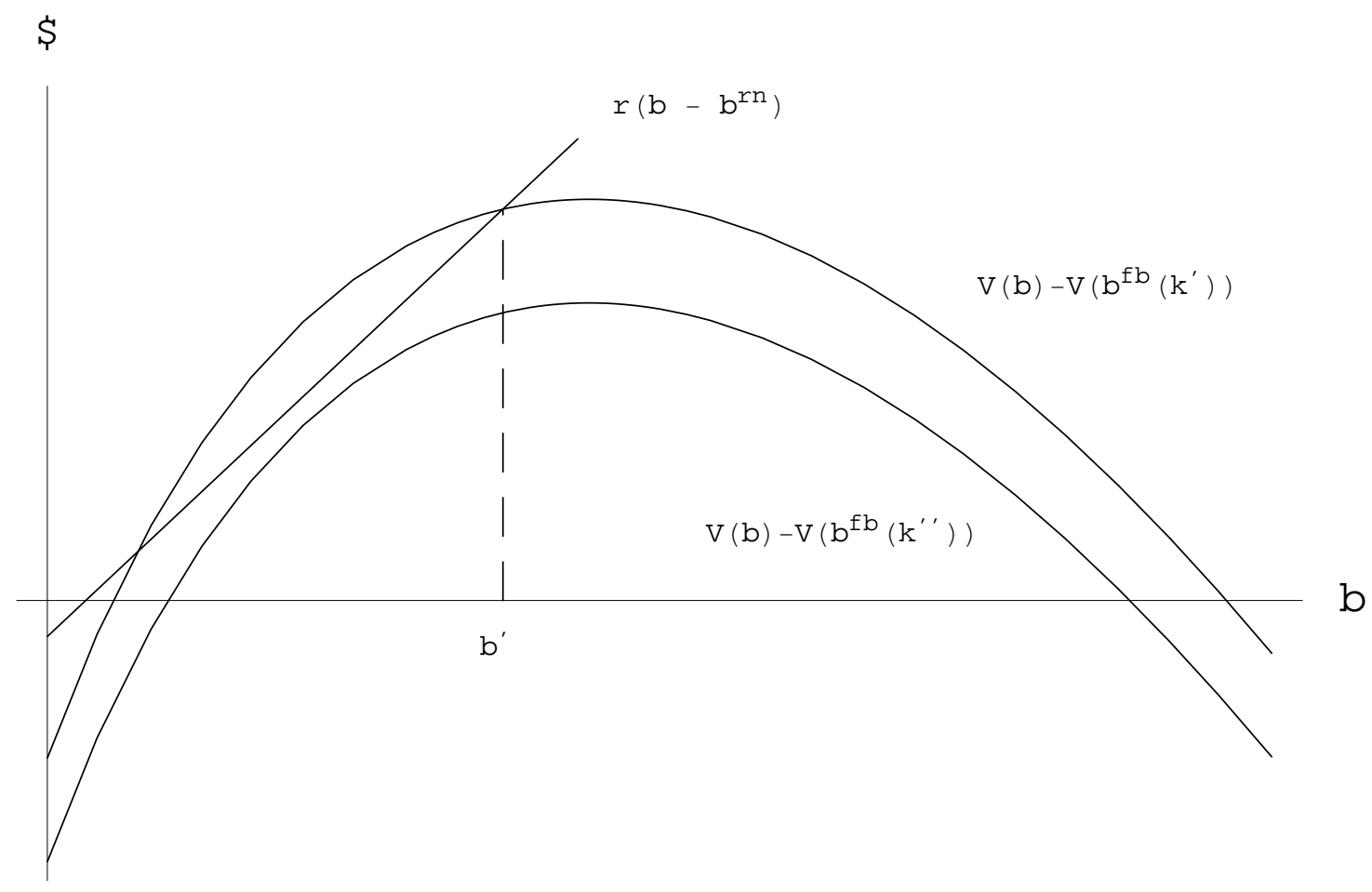

Figure 8: An increase in $k$ from $k^{\prime}$ to $k^{\prime \prime}$ causes the fallback position to become so good that reputational governance is no longer feasible.

firm's reputation does not exceed the gains from reneging for any $b$, so reputation cannot be used as an enforcement mechanism. The no-mimic constraint provides an alternative governance mechanism for these values of $k$. Hence, equilibrium bonuses are given by $b^{f b}(k)$, which is increasing in $k$. Finally, if $k>k_{2}$, then the bonus associated with the no-mimic constraint is so large that the firm prefers offering the full-insurance contract or shutting down.

To summarize the comparative statics in this subsection, we find a non-monotonic relationship between the set of equilibrium bonus amounts and the degree of the firm's myopia, $k$. For small $k$, increases in $k$ do not affect the fallback position, and hence do not affect the set of bonus amounts that are feasible under reputational governance. For larger $k$, the fallback position improves as the firm become more myopic, which means that the largest feasible bonus amount falls as $k$ increases. As $k$ increases even further, reputational governance may become infeasible. Since the no-mimic constraint provides an alternative governance mechanism and bonuses satisfying this constraint increase with $k$, we have that bonus amounts increase with $k$ in this case. Note that, as in the analysis of Section 2, it is possible that the bonus a successful 
firm must pay in order to distinguish itself from a firm with a failed project may exceed the second best. For even larger values of $k$, the no-mimic bonus may become so large that the firm prefers to offer a pooling contract, or shut down.

\subsubsection{Case 2: $b^{r n}=b^{f b}(k)$}

As an alternative specification of the market's beliefs when observing an out-of-equilibrium bonus payment, we assume that the market assesses the probability that the firm's current project is successful to be zero if $b<b^{f b}(k)$ and one otherwise. This specification of beliefs holds some intuitive appeal, since if the relational contract has been breached in the past, a firm with a failed project would be willing to pay a bonus of up to $b^{f b}(k)$ if doing so would convince the market that the firm's project was successful. ${ }^{17}$ In this case, a firm that chooses to renege on its relational contract will elect to pay bonus $b^{f b}(k)$. The reputational governance constraint is given by

$$
V(b)-\max \left[0, V\left(b^{f b}(k)\right)\right] \geq r\left(b-b^{f b}(k)\right)
$$

Given that both sides of $\left(\mathrm{RG}^{\prime \prime \prime}\right)$ move the same direction with changes in $k$, how does the largest credible relational-contract bonus vary with $k$ ? To start, suppose $V(0)<0$, so the firm is better off shutting down than offering the full-insurance contract. Then for $k<k_{0}$, we have $b^{f b}(k)=0$ so $\left(\mathrm{RG}^{\prime \prime \prime}\right)$ again reduces to the no-signaling reputational governance constraint from (RG). This means that the largest bonus credible under reputational governance does not vary with $k$ on this interval.

Now suppose that $k \geq k_{0}$. We define $k_{1}$ implicitly as the solution to

$$
V^{\prime}\left(b^{f b}\left(k_{1}\right)\right)=r
$$

Since $b^{f b}$ is monotone in $k$ for $k \in\left[k_{0}, k_{2}\right]$ and $V$ is differentiable and strictly concave, this equation has a unique solution. In Figure 9, we show how the two sides of (RG'" $)$ shift as $k$ increases for $k \in\left[k_{0}, k_{1}\right)$. Both $r\left(b-b^{f b}(k)\right)$ and $V(b)-V\left(b^{f b}(k)\right)$ shift downward as $k$ increases from $k^{\prime}$ to $k^{\prime \prime}$. Note, however, that $r\left(b-b^{f b}(k)\right)$ shifts at the rate $-r \frac{d}{d k} b^{f b}(k)$, while $V(b)-V\left(b^{f b}(k)\right)$ shifts at rate $-V^{\prime}\left(b^{f b}(k)\right) \frac{d}{d k} b^{f b}(k)$. By concavity of $V$, we have that $V^{\prime}\left(b^{f b}(k)\right)>$ $r$ when $k<k_{1}$, so $V(b)-V\left(b^{f b}(k)\right)$ shifts downward faster. As depicted in the figure, the largest feasible bonus shifts downward as $k$ increases. At the level of intuition, an increase in $k$ makes

\footnotetext{
${ }^{17}$ We show in the appendix, however, that given these beliefs, there do exist equilibria that fail the Cho and Kreps (1987) Intuitive Criterion.
} 


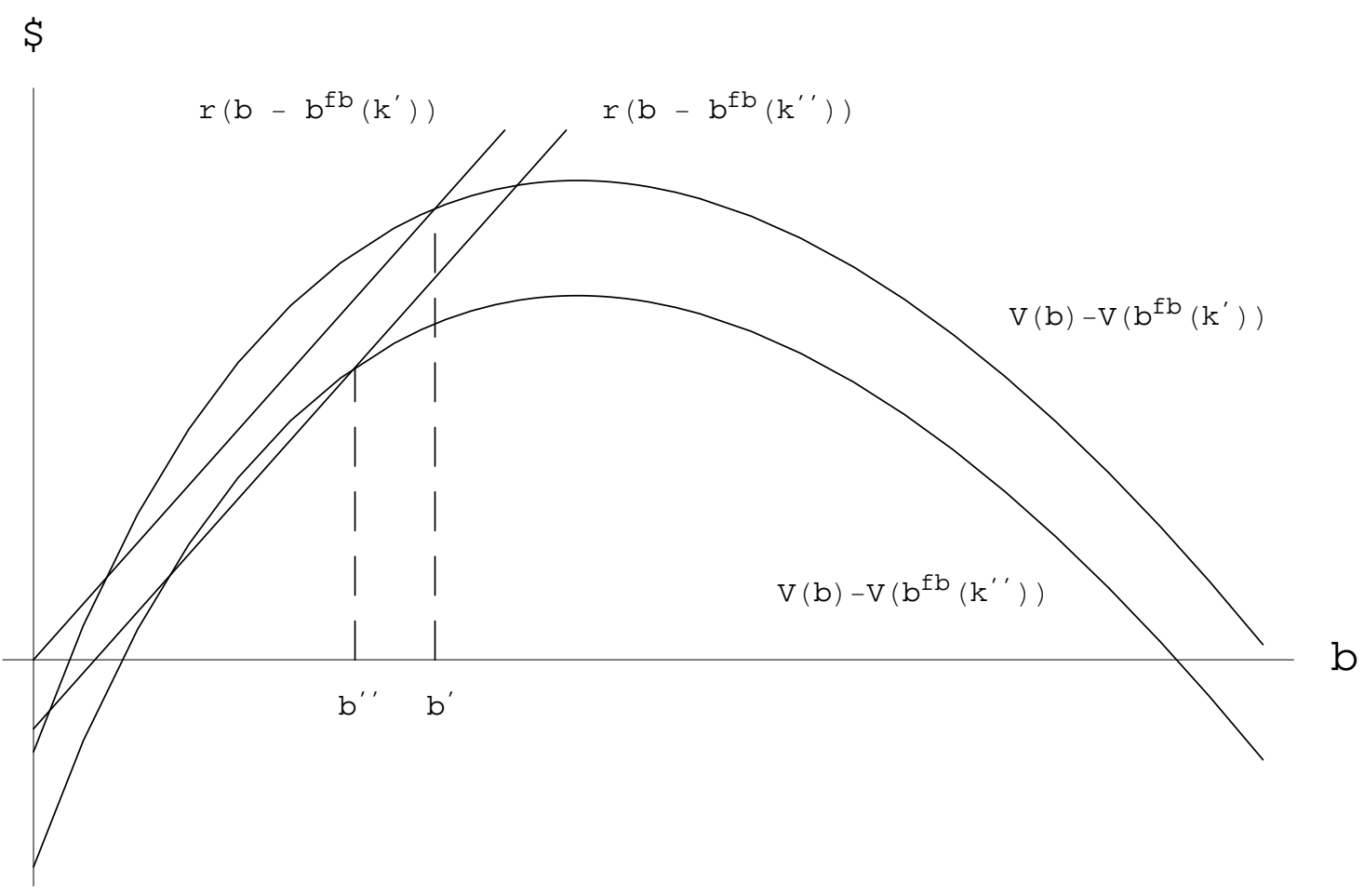

Figure 9: When $k$ increases from $k^{\prime}$ to $k^{\prime \prime}$ (where $k_{0} \geq k^{\prime}<k^{\prime \prime}<k_{1}$ ), the largest credible bonus decreases from $b^{\prime}$ to $b^{\prime \prime}$.

the immediate payoff from reneging smaller, since the bonus the successful firm must pay to distinguish itself from a firm with a failed project gets larger. However, the increase in $k$ also improves the fallback position, which shrinks the magnitude of the punishment the manager can inflict on the firm in the event that the firm reneges. Concavity of $V$ implies that for small $k$, increases in $k$ (and thus increases in the bonus the firm could commit to in the event that the relational contract is breached) mean large improvements in the fallback position faced by the parties if the firm reneges. Hence, for small $k$ the improvement in the fallback position dominates the reduction in the gains from reneging. The net temptation to renege increases, and the firm is able to commit to smaller bonuses.

Note that, as in the discussion in 4.2 .1 above, it is possible for the $V(b)-V\left(b^{f b}(k)\right)$ curve to drop completely below the $r\left(b-b^{f b}(k)\right)$ line for $k<k_{1}$. In this case, the fallback position is so good that the firm's reputation is insufficiently valuable to support any bonus larger than $b^{f b}(k)$. When the largest credible bonus drops to $b^{f b}(k)$, further increases in $k$ lead to larger bonuses, since $b^{f b}(k)$ is increasing in $k$ for $k \in\left[k_{0}, k_{2}\right]$. 


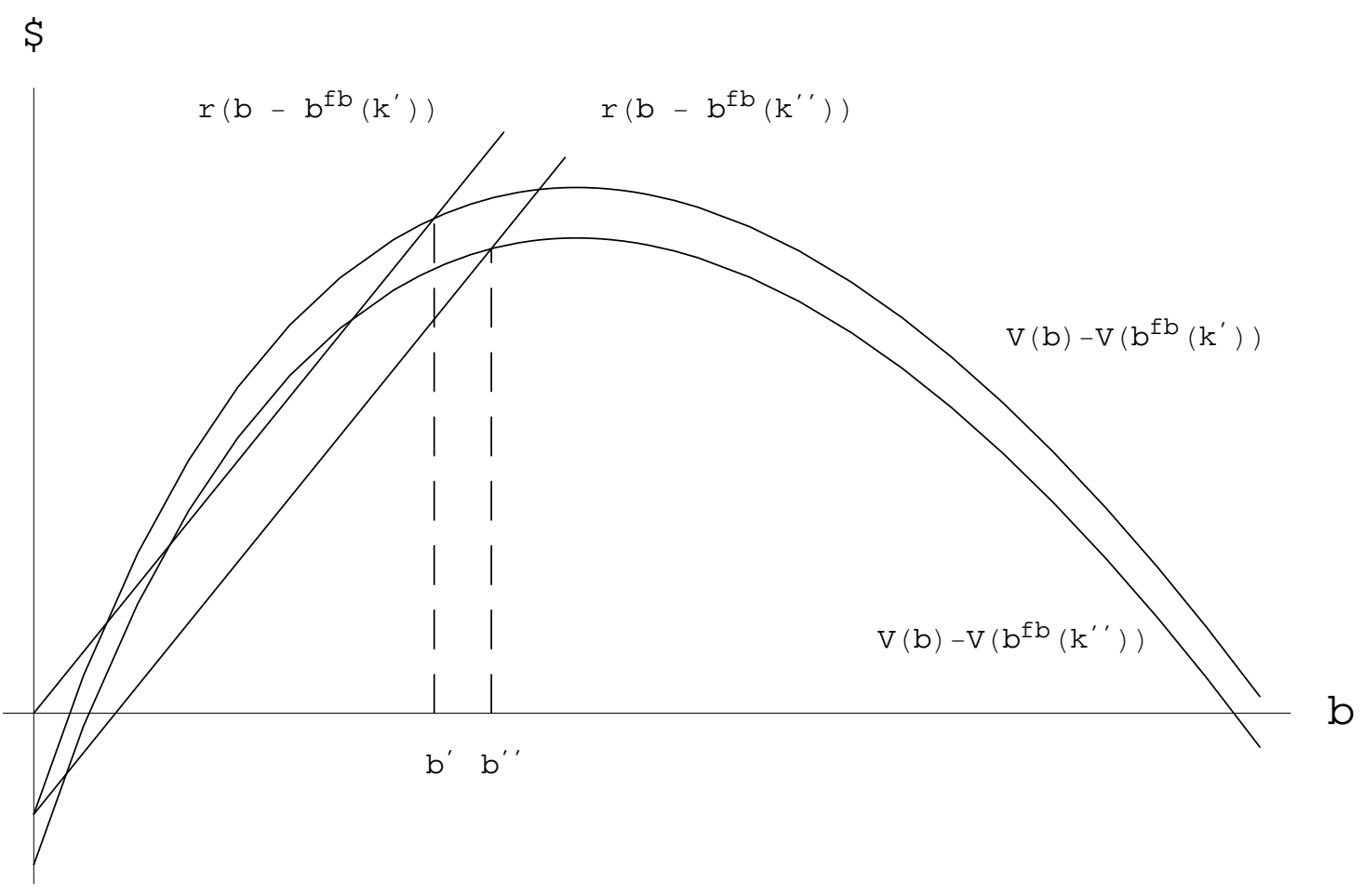

Figure 10: When $k$ increases from $k^{\prime}$ to $k^{\prime \prime}$ (where $k_{1}<k^{\prime}<k^{\prime \prime} \leq k_{2}$ ), the largest credible bonus increases from $b^{\prime}$ to $b^{\prime \prime}$.

Now let $k \geq k_{1}$. Assume, to start, that reputational governance is still feasible at $k_{1}$; that is, $V(b)-V\left(b^{f b}(k)\right)$ has not fallen below the $r\left(b-b^{f b}(k)\right)$ curve at $k_{1}$. Then, the largest credible bonus for $k=k_{1}$ is still determined by $\left(\mathrm{RG}^{\prime \prime \prime}\right)$. It is still the case that $V(b)-V\left(b^{f b}(k)\right)$ and $r\left(b-b^{f b}(k)\right)$ are decreasing with $k$; however, since $V^{\prime}$ is now less than $r$, the largest feasible bonus is increasing on this range. In Figure 10, we depict an increase in $k$ from $k^{\prime}$ to $k^{\prime \prime}$, and show that the largest feasible bonus increases from $b^{\prime}$ to $b^{\prime \prime}$. For these higher values of $k$, the parties' fallback position improves more slowly with $k$. The reduction in the immediate gain from reneging now outweighs the improvement in fallback position, and the firm is less tempted to renege on a relational contract. This means the manager can trust the firm's promise to pay a larger bonus. Note that if reputational governance is not feasible at $k_{1}$ (so that $V(b)-V\left(b^{f b}(k)\right.$ ) is everywhere below $r\left(b-b^{f b}(k)\right)$ at $\left.k_{1}\right)$, then the largest credible bonus offer is always $\left.b^{f b}(k)\right)$, which is increasing with $k$. We conclude that bonus offers are increasing with $k$ for $k \in\left[k_{1}, k_{2}\right]$. Finally, note again that if $k>k_{2}$, then the bonus associated with the no-mimic constraint is so large that the firm prefers either offering the full-insurance, pooling contract, or shutting down. 
To summarize this subsection, we again find a non-monotonic relationship between the set of equilibrium bonus amounts and the degree of the firm's myopia. For small $k$, increases in $k$ do not change the fallback position but do reduce the gains from reneging. This makes reputation easier to sustain, and implies that the largest feasible bonus amounts increase with $k$. For larger $k$, both the value of the firm's reputation and the gains from reneging fall as $k$ increases. Initially, the value of reputation falls faster, reducing the largest feasible bonus. Then, the gains from reneging fall faster, which increases the largest feasible bonus. As above, reputational governance may become infeasible for large $k$. In this event, bonus amounts are increasing in $k$. It remains possible that the bonus a successful firm must pay in order to distinguish itself from a firm with a failed project may exceed the second best. For even larger values of $k$, the no-mimic bonus may become so large that the firm prefers to offer a pooling contract or shut down.

While we have focused on two specific instances of the market's beliefs when observing offequilibrium-path bonus payments, our findings are robust to many other specifications of these beliefs. As long as the smallest bonus that credibly conveys project success does not increase too rapidly for small $k$, there will be a range of values of $k$ for which the improvement in the value of the fallback position dominates the reduction in the gains from reneging. This implies that the largest credible reputation-backed bonus offer will decrease with $k$ on this range.

\subsection{Comparison to Prior Signaling Models}

Recall that in most signaling models featuring myopic corporate behavior, firms take actions that hurt long-run profitability in an attempt to boost short-run share prices. When firms become more focused on short-run share prices, they engage in more of such activity, which results in even lower profits. Our model yields different results on two dimensions.

First, we find that as the firm becomes more focused on short-run share prices, it may engage in less of the signaling activity, which in this case is paying bonuses for project success. This result arises because of the effect of the firm's incentive to choose wage payments strategically on its relationship with the manager. In both 4.2 .1 and 4.2 .2 above, there exists a range of values over which increases in $k$ improve the fallback contracting position, thus limiting the efficacy of reputational governance and reducing the efficiency of the firm's contract with its manager. As in more standard signaling models, increases in myopia are, in this case, associated with reductions in profits. Our finding here parallels that of Baker et al. (1994), who show that as the quality of a verifiable performance measure improves, it may become harder to use reputation 
to enforce bonuses based on subjective performance measures.

Second, while we do identify conditions under which increases in myopia lead to higher levels of the signaling activity, we find that profits may actually increase with myopia on these regions. This result also arises because of the effect of the firm's incentive to choose wage payments strategically on its relationship with the manager. When reputational governance is infeasible, the firm relies on the no-mimic constraint to govern the contract. For small $k$, this governance may not be sufficiently strong to allow the firm to achieve the second-best bonus; in this case, increases in $k$ improve efficiency by pushing the contract toward the second best.

As we indicated above, one way to view our results is to contrast the different inefficiencies arising from shareholders' two forms of timing-related preferences: "impatience" and "myopia." In the stage game studied in Section 2, myopic behavior on the part of the firm pushes the contract away from the second best, while in the repeated game of Section 3, it is impatience that limits the efficacy of reputation as a governance mechanism. Combining these models, we find that myopic behavior on the part of the firm can either exacerbate or mitigate inefficiencies arising from impatience. While impatience may prevent the firm from achieving the second best under reputational governance, myopia can exacerbate this problem by making the fallback position more attractive. However, if the firm is so impatient so that no reputation-backed bonus offer is credible, then myopia can mitigate the problem by providing an alternative governance mechanism.

\section{Discussion}

\subsection{Choice of Compensation Instruments}

One open question regarding executive compensation practices is what factors determine the mix of instruments used to reward executives. Executives are commonly paid using a wide variety of instruments, including cash bonuses, equity ownership, and options, and there has been little work by financial economists to determine factors underlying firms' choices over these instruments. While we do not attempt a full analysis of the determinants of firms' choices over pay instruments, it is clear that any such analysis must begin with a discussion of how the properties of equity-based instruments and discretionary bonus payments differ. Our model

suggests one such point of difference: whereas payments made under bonus plans can convey 
information to market participants, equity-based instruments do not. ${ }^{18}$

A firm's choice over the mix of discretionary payments vs. equity-based instruments would presumably be determined by a comparison of costs and benefits. ${ }^{19}$ Since equity-based instruments suffer from a moral hazard in teams problem and are subject to market-based fluctuations in value, a firm may be better able to tailor rewards to the executive's actions using discretionary payments. However, if there are efficiency losses due to the firm's incentives to choose discretionary payments strategically, then a firm could potentially be better off if it can commit to provide incentives using equity-based instruments. This insight may offer a starting point for an analysis of the determinants of pay instruments.

\subsection{Compensation Disclosure Rules}

We next discuss potential implications of our model regarding the effects of changes in compensation disclosure requirements for top managers. In the United States, the SEC requires publicly held firms to disclose compensation amounts for top executives. In 1992, the SEC implemented a major overhaul of compensation disclosure requirements. The new rules require greater standardization of the compensation information disclosed and emphasize the linkage between pay and performance. Among other things, firms must present tables detailing the annual and long-term compensation of the firm's five most highly paid executives, estimates of the value of executive stock options, comparisons of the firm's performance to industry and market benchmarks, and details about the performance measures used to evaluate managers.

The fact that disclosure rules are necessary to induce firms to reveal compensation amounts suggests that in the absence of such rules, firms would choose not to disclose these figures. Two potential costs of disclosure have been suggested in the literature on executive pay practices. First, Murphy (1992) argues that managers bear "political costs" when large pay amounts are disclosed. Other authors (see, for example, Quinn (1995)) have argued that a firm may not want to disclose compensation amounts or performance standards for fear of compromising its competitive position. Once disclosure rules are implemented, however, market participants can

\footnotetext{
${ }^{18}$ Of course, discretionary grants of equity-based instruments may convey information. However, since changes in an executive's wealth stemming from his pre-existing "stock" of equity-based instruments are simply a known function of publicly observable measures of firm performance, no non-public information regarding current performance is conveyed by changes in the value of these instruments.

${ }^{19}$ Institutional factors may also affect this choice. In the U.S., for instance, payments to executives in excess of $\$ 1$ million are not tax-deductible unless they are demonstrably performance based.
} 
observe the payments made by the firm to the manager. If an incentive contract features a one-to-one mapping from non-public information to wage payments, then market participants may attempt to infer the information from these payments.

While a full analysis of the welfare implications of compensation disclosure requirements is beyond the scope of this paper, we can offer some insight regarding the possible effects of these rules. Our analysis suggests that firms that are required to disclose will do so keeping in mind the effect of their disclosure on the value of the firm. Within the context of our model, one can think of the effects of disclosure rules as increasing the value of $k$. If unmodeled political or competitive costs caused firms to elect not to disclose compensation amounts prior to the imposition of a disclosure requirement, then there is no scope for firms to choose compensation amounts strategically. This would correspond to a case of $k=0$. Once the disclosure rule is in place, the firm may wish to act strategically, so that $k>0$.

While our model does not offer a definitive prediction as to how bonus amounts should change as $k$ increases, we can apply our analysis to interpret some empirical evidence on changes in executive pay practices subsequent to the 1992 changes in disclosure rules. Perry and Zenner (1998) examine changes in executive pay arrangements in response to changes in disclosure rules and report that both compensation levels and the sensitivity of compensation to firm performance increased in response to changes in the regulatory environment. They also report that the increases in pay-performance sensitivity are higher in firms with lower inside equity ownership, which, under the assumption that insiders are less eager to sell, may suggest that increases in contingent pay associated with the disclosure rules are larger for firms that have a greater concern for short-run share prices. Johnson, Porter and Shackell (1997) report similar findings in a study of how stakeholder pressure affects compensation arrangements.

While some observers of executive compensation would applaud any increase in the sensitivity of pay to performance, one possibility suggested by our model is that these changes could actually reduce welfare. This would correspond to a situation where the second-best bonus does not satisfy the no-mimic constraint arising as a result of the disclosure requirement; in this case, the resulting contract induces too much effort and places excessive risk on the manager. It is also possible, however, to construct instances of our model in which increases in the sensitivity of pay to performance associated with stricter disclosure rules result in higher welfare. 


\section{Conclusion}

In this paper, we offer a new perspective on managerial compensation arrangements by suggesting that firms may be able to condition payments to managers on information that is not available to those outside the firm. If relational incentive contracts specify a mapping from private information to wage payments, then market participants may use the magnitude of such payments to infer the non-public information. Given this, firms may make incentive compensation decisions strategically, with an eye toward affecting outsiders' perceptions of the value of the firm. We study equilibria of a simple signaling game in which payments from a firm to a manager convey information regarding the future payoffs to the firm's shareholders. A primary finding is that the nature of the firm's contracting relationship with its manager is affected by the firm's incentive to choose wage payments strategically, and that the resulting relationship between feasible bonus amounts and the degree of the firm's myopia is non-monotonic.

Future research could proceed down several avenues. First, it may be possible to combine elements of our model with that of Baker et al. (1994) to study how the interplay among public and non-public measures of managerial performance is affected by a publicly traded firm's incentive to choose wage payments strategically. Second, our observation that discretionary bonus payments may convey information to market participants may provide a starting point for a theory of firms' choices over the mix of compensation instruments. Third, our model suggests one way in which compensation disclosure requirements may affect firms' relationships with top managers. It may be possible to build on this notion to develop a more detailed analysis of such disclosure rules. 


\section{Appendix}

\section{Proofs from Section 2}

We begin by defining some additional notation. Let $\tilde{q}(s, b)$ be the market's belief as to the probability the firm's project is successful when it observes the salary and bonus payments $(s, b)$. Let $\Pi$ represent the average payoff to original shareholders when the firm offers contract $(s, b)$, given the market's inference $\tilde{q}$ about the outcome of the firm's project after observing salary and bonus payments. Formally,

$$
\begin{aligned}
\Pi[s, b, \tilde{q}(s, b), \tilde{q}(s, 0)]= & p\left(e^{*}(s, b)\right)\left[k \tilde{q}(s, b)\left(\pi_{s}-\pi_{f}\right)+(1-k)\left(\pi_{s}-\pi_{f}\right)-b\right] \\
& +\left(1-p\left(e^{*}(s, b)\right)\right) k \tilde{q}(s, 0)\left(\pi_{s}-\pi_{f}\right)+\pi_{f}-s .
\end{aligned}
$$

We define a solution concept for the stage game outlined in Section 2 above, and then prove three propositions that characterize the relationship between equilibrium contracts and the firm's degree of myopia. An action for the firm in this game consists of a contract offer $(s, b)$ made at the beginning of the game and a bonus payment $b$ made after the project outcome has been privately revealed. An action for the manager consists of a participation decision based on the firm's contract offer and an effort choice. An action for the market is a mapping from observed salary and bonus amounts to a valuation of the firm's shares. In analyzing this game, we assume an unmodeled governance mechanism allows the firm to commit to paying the second-best bonus in the event of project success. The purpose of this assumption is to focus attention on how the no-mimic constraint affects contracts.

A Compensation-Signaling Equilibrium (CSE) is a perfect Bayesian equilibrium of this game satisfying two refinements. We require that the market's beliefs as to the project's success or failure cannot be affected by the salary payment $s$, as such payments are made prior to the realization of project uncertainty. We also require the equilibrium to satisfy the Cho and Kreps (1987) Intuitive Criterion, which eliminates all equilibria except those with the least inefficient signaling. A CSE is a pure strategy profile that satisfies the following properties:

1. Taking the mapping from observed wage payments to market values as given, paying bonus $b$ must maximize the average payoff to original shareholders conditional on project success and paying bonus 0 must maximize the average payoff to original shareholders conditional on project failure.

2. Taking the mapping from wage payments to market value, the firm's choice of bonus payment conditional on project outcome, and the salary offer as given, the manager's participation and effort decisions must maximize his expected utility.

3. Taking the market's mapping from observed bonus payments to market values and the manager's participation and effort decisions as given, the wage contract offered to the manager at the beginning of the game must maximize the ex ante average payoff to the firm's original shareholders.

4. The market's assessment of the outcome of the firm's project conditional on the bonus payment made to the manager must be correct. 
5. For all $b$ and $s \neq s^{\prime}, \tilde{q}(s, b)=\tilde{q}\left(s^{\prime}, b\right)$.

6. Given a contract $(s, b)$, for all $b^{\prime}<b$ such that $\pi_{f}>k \pi_{s}+(1-k) \pi_{f}-b^{\prime}$,

$$
\Pi[s, b, 1,0]>\Pi\left[s\left(b^{\prime}\right), b^{\prime}, 1,0\right] .
$$

In words, this statement says that for any $b^{\prime}<b$ such that a firm with a failed project would prefer to pay its manager no bonus rather than $b^{\prime}$ even if paying $b^{\prime}$ would induce the market to believe the firm's project had succeeded, it must be that the expected profit from offering the CSE contract $(s, b)$ is higher than the expected profit from offering $\left(s\left(b^{\prime}\right), b^{\prime}\right)$, where the function $s(\cdot)$ is as defined in Section 3.

Property (6) is a refinement similar in spirit to the Cho and Kreps (1987) Intuitive Criterion; its role is to rule out equilibria with "excessive" signaling. Such an equilibrium features a bonus contract $(s, b)$ that satisfies the first five conditions of the CSE but imposes a higher level of risk on the manager than other contracts that satisfy the individual rationality and no-mimic constraints. This equilibrium is sustained by a market beliefs assessing probability one to a failed project if the firm makes a bonus payment below $b$. Given this mapping of bonus payments to market values, the firm would not offer an alternate contract $\left(s\left(b^{\prime}\right), b^{\prime}\right)$, with $b^{\prime}<b$, even if such a contract satisfies the no-mimic constraint and yields higher profits.

We now offer three propositions to characterize the relationship between equilibrium bonus contracts and the firm's degree of myopia.

Proposition 1 For $k \in\left[0, \frac{b^{*}}{\pi_{s}-\pi_{f}}\right]$, an efficient separating CSE exists and there does not exist a contract other than the second-best that can be part of a CSE.

Proof: We first construct a separating CSE wherein the firm offers the second-best contract. We then show that no other contract can be part of a CSE over this range of $k$.

To start, we specify the market's mapping from bonus payments to beliefs as to the project outcome. Suppose that if the market observes a bonus payment $b^{*}$ or higher, it assesses the probability that the firm's project has succeeded to be one. Otherwise, the market assesses the probability of project success to be zero.

To establish property (1), note that a firm with a successful project is prevented by an unmodeled governance mechanism from mimicking a firm with a failed project. A firm with a failed project finds that the no-mimic constraint is satisfied, and chooses not to pay the success bonus $b^{*}$. To see this, note that, given the specified mapping from bonus payments to firm valuation, the no-mimic constraint is given by

$$
b-k\left(\pi_{s}-\pi_{f}\right) \geq 0
$$

For $k \in\left[0, \frac{b^{*}}{\pi_{s}-\pi_{f}}\right]$, this constraint is satisfied. Since bonus payments fully reveal project outcomes, the market valuations conditional on bonus payments specified above are correct. This establishes property 
(4). Properties (2), (3), (5) and (6) are satisfied by construction. The second-best contract and the specified mapping from bonus payments to valuations therefore constitute a CSE.

Now we show that no other contract can be part of a CSE for $k \in\left[0, \frac{b^{*}}{\pi_{s}-\pi_{f}}\right]$. Choose an arbitrary $b<b^{*}$ and consider $(s(b), b)$ as a candidate for a CSE contract. There are two cases to consider. First, suppose $k \in\left[\frac{b}{\pi_{s}-\pi_{f}}, \frac{b^{*}}{\pi_{s}-\pi_{f}}\right]$. By construction, $(s(b), b)$ cannot satisfy the no-mimic constraint, and a firm with a failed project will pay bonus $b$. Hence, $(s(b), b)$ violates CSE property (1). Second, suppose $k \in\left[0, \frac{b}{\pi_{s}-\pi_{f}}\right)$. Then $(s(b), b)$ cannot be an equilibrium since it fails condition (3); the firm's profits are strictly higher if it offers the second-best contract $\left(s^{*}, b^{*}\right)$.

Now select an arbitrary $b>b^{*}$. Given the restriction on the market's belief imposed by the refinement in condition (6), the firm earns strictly higher profits if it offers the second-best contract $\left(s^{*}, b^{*}\right)$. Hence, a contract offering bonus $b$ cannot be a CSE. $\square$

For our second proposition, we need additional notation. Let $\hat{k}$ be defined implicitly as the $k$ solving

$$
\Pi\left[s\left(k\left(\pi_{s}-\pi_{f}\right)\right), k\left(\pi_{s}-\pi_{f}\right), 1,0\right]=\max [0, \Pi[\bar{s}, 0,1,0]] .
$$

That is, $\hat{k}$ is the value of $k$ for which the firm's profits when offering the contract featuring the smallest bonus that satisfies the no-mimic constraint are the same as its profits when offering the full-insurance contract. Referring back to Figure $4, \hat{k}$ is the value of $k$ for which the (NM) line passes through the intersection of the (IR) curve and the isoprofit curve corresponding to the full-insurance contract. If the full-insurance contract yields negative profits, then the $\hat{k}$ equates the profits under the no-mimic contract to zero.

Proposition 2 For $k \in\left(\frac{b^{*}}{\pi_{s}-\pi_{f}}, \min [\hat{k}, 1]\right]$, an inefficient separating CSE exists. For a given $k$, the separating contract is unique, features bonus payment $k\left(\pi_{s}-\pi_{f}\right)$, and induces higher effort and places more risk on the agent than the second-best contract. As $k$ increases over this interval, welfare decreases.

Proof: We first construct the equilibrium, then show that no other contract can be part of a CSE. Suppose that if the market observes a bonus payment $k\left(\pi_{s}-\pi_{f}\right)$ or higher, it assesses the probability that the firm's project has succeeded to be one. Otherwise, the market assesses the probability of project success to be zero. The no-mimic constraint is satisfied with equality for this bonus, so CSE condition (1) is met. Given this, the market's assessment of the project outcome conditional on the bonus is correct, so (4) is met as well. Properties (2), (3), (5) and (6) are satisfied by construction. The contract $\left(s\left(k\left(\pi_{s}-\pi_{f}\right)\right), k\left(\pi_{s}-\pi_{f}\right)\right)$ and the specified mapping from bonus payments to valuations therefore constitute a CSE.

To show that no other contract can be part of a CSE, we first consider an arbitrary $b<k\left(\pi_{s}-\pi_{f}\right)$. A contract featuring this bonus does not satisfy the no-mimic constraint, so a firm with a failed project would pay the bonus and the contract violates CSE condition (1). Next consider an arbitrary $b>$ $k\left(\pi_{s}-\pi_{f}\right)$. Such a contract violates condition (6), since the firm earns strictly higher profits if it offers 
the contract with bonus $k\left(\pi_{s}-\pi_{f}\right)$. Hence, no contract offering a bonus other than $k\left(\pi_{s}-\pi_{f}\right)$ can be an equilibrium.

Since bonus levels are increasing in $k$, it follows directly that the manager exerts more effort and is exposed to more risk. To see that welfare is decreasing in $k$, first note that the payoffs to the manager and the stock market participants do not vary with $k$. Hence, profits are the only variable component of welfare. Since the firm's objective function is concave and the bonus associated with the inefficient separating contract is both $(i)$ greater than the second-best bonus and $(i i)$ increasing with $k$, profit (and hence welfare) decreases with $k$.

Proposition 3 If $\hat{k}<1$, then for $k \in(\hat{k}, 1]$, either there exists a CSE featuring pooling, or the firm shuts down.

Proof: First note that any contract paying bonus $b<k\left(\pi_{s}-\pi_{f}\right)$ violates CSE condition (1). A firm offering a contract paying a bonus larger than $k\left(\pi_{s}-\pi_{f}\right)$ earns profits $\Pi\left[s\left(k\left(\pi_{s}-\pi_{f}\right)\right), k\left(\pi_{s}-\pi_{f}\right), 1,0\right]$, which, by the definition of $\hat{k}$, is less than the profit it earns from offing the pooling contract $(s(0), 0)$, or shutting down. CSE condition (3) implies that the firm either offers a contract featuring zero bonus, or shuts down. $\square$

\section{Proofs from Section 4.1}

We first offer some definitions. Let

$$
b_{0}=\left\{\begin{array}{cl}
\text { smallest } b \text { satisfying } V(b)=0 & \text { if } V(0)<0 \\
0 & \text { otherwise }
\end{array}\right.
$$

Also, let $b_{1}$ be the largest $b$ satisfying $V(b)=V\left(b_{0}\right)$. In the case where $V(0)<0, b_{1}$ is the bonus at which the firm is indifferent between the separating equilibrium featuring bonus $b_{1}$ and shutting down. When $V(0) \geq 0, b_{1}$ is the bonus at which the firm is indifferent between the separating contract featuring bonus $b_{1}$ and the pooling contract featuring bonus zero. Referring back to Equation (6), it is the case that $b_{1}=\hat{k}\left(\pi_{s}-\pi_{f}\right)$. For a fixed $k \in[0,1]$, define $\tilde{b}(k)$ as the smallest $b$ satisfying

$$
b=k\left(\pi_{s}-\pi_{f}\right)-\frac{1-k}{r}[V(b)-\max [0, V(0)]] .
$$

Note that since $V$ is strictly concave, there are at most two solutions to this equation. Define $b^{f b}(k)$ as

$$
b^{f b}(k)= \begin{cases}\tilde{b}(k) & \text { if } \tilde{b}(k) \in\left[b_{0}, b_{1}\right] \\ 0 & \text { otherwise. }\end{cases}
$$

Proposition 4 The function $b^{f b}(k)$ has the following properties:

(i) If $V(0)<0$, then $b^{f b}(k)=0$ for all $k \in\left[0, b_{0} /\left(\pi_{s}-\pi_{f}\right)\right)$. 
(ii) $b^{f b}\left(\frac{b_{0}}{\pi_{s}-\pi_{f}}\right)=b_{0}$.

(iii) $b^{f b}\left(\frac{b_{1}}{\pi_{s}-\pi_{f}}\right) \leq b_{1}$.

(iv) Let $k_{2}=\max \left\{k \mid\right.$ there exists $b \in\left[b_{0}, b_{1}\right]$ such that $\left.b<k\left(\pi_{s}-\pi_{f}\right)-\frac{1-k}{r}[V(b)-\max [0, V(0)]]\right\}$. Then $k_{2} \geq b_{1} /\left(\pi_{s}-\pi_{f}\right)$ and $b^{f b}(k)$ is strictly increasing for $k \in\left[b_{0} /\left(\pi_{s}-\pi_{f}\right), \min \left[k_{2}, 1\right]\right]$.

(v) If $k_{2}<1$, then $b^{f b}(k)=0$ for all $k \in\left(k_{2}, 1\right]$

Proof: We show (ii) first. Substitute $k=b_{0} /\left(\pi_{s}-\pi_{f}\right)$ into (7) to get

$$
b-b_{0}=-\frac{1-k}{r}[V(b)-V(0)]
$$

and note that both sides equal zero when $b=b_{0}$. To show that this is the smallest solution, we rely on the concavity of $V$ : since $V^{\prime}\left(b_{0}\right)>0$ (by the assumption that it is efficient to pay positive bonuses), the slope of the left side of (8) is greater than the slope of the right side at $b=b_{0}$. Since $-V$ is convex, its slope is everywhere increasing and there can be no solution to the left of $b=b_{0}$.

We next show $(i)$. Select an arbitrary $k \in\left[0, b_{0} /\left(\pi_{s}-\pi_{f}\right)\right)$. Note first that at this $k, b_{0}>k\left(\pi_{s}-\pi_{f}\right)>$ 0 . Also, $\frac{1-k}{r} V\left(b_{0}\right)=0$, by the definition of $b_{0}$. Hence,

$$
b_{0}>k\left(\pi_{s}-\pi_{f}\right)-\frac{1-k}{r} V\left(b_{0}\right) .
$$

Note also that since $V(0)<0$,

$$
0<k\left(\pi_{s}-\pi_{f}\right)-\frac{1-k}{r} V(0) .
$$

Since both the right and left sides of (7) are continuous in $b,(9)$ and (10) together imply that the smallest solution to $(7)$ is less than $b_{0}$. Hence $b^{f b}(k)=0$.

To show (iii), we substitute $k=b_{1} /\left(\pi_{s}-\pi_{f}\right)$ into (7) to get

$$
b-b_{1}=-\frac{1-k}{r}[V(b)-V(0)]
$$

and note that both sides equal zero when $b=b_{1}$. If this is the smallest solution, then $b^{f b}\left(b_{1} /\left(\pi_{s}-\pi_{f}\right)\right)=$ $b_{1}$. If not, then $\tilde{b}<b_{1}$, which then implies that $b^{f b}\left(b_{1} /\left(\pi_{s}-\pi_{f}\right)\right)<b_{1}$.

To establish $(i v)$, we first show that if $k$ is such that $\tilde{b}(k) \in\left[b_{0}, b_{1}\right]$, then $\tilde{b}^{\prime}(k)>0$. Since $\tilde{b}(k)$ is welldefined on the interval $\left[b_{0} /\left(\pi_{s}-\pi_{f}\right), \min \left[k_{2}, 1\right]\right]$, we use the implicit-function theorem to differentiate $(7)$ implicitly:

$$
\tilde{b}^{\prime}(k)=\left(\pi_{s}-\pi_{f}\right)-\frac{1-k}{r} V^{\prime}(\tilde{b}(k)) \tilde{b}^{\prime}(k)+\frac{1}{r}[V(\tilde{b}(k))-\max [0, V(0)]]
$$

which simplifies to

$$
\tilde{b}^{\prime}(k)=\frac{\left(\pi_{s}-\pi_{f}\right)+\frac{1}{r}[V(\tilde{b}(k))-\max [0, V(0)]]}{1+\frac{1-k}{r} V^{\prime}(\tilde{b}(k))} .
$$


The numerator is positive for all $\tilde{b}(k) \in\left[b_{0}, b_{1}\right]$. To establish that denominator is positive as well, we note that the slope of the left side of $(7)$ at $\tilde{b}(k)$ is one and the slope of the right side at $\tilde{b}(k)$ is $-\frac{1-k}{r} V^{\prime}(\tilde{b}(k))$. Since $\tilde{b}$ is the smallest solution of (7) for this value of $k$ and $V$ is concave, it must be that $-\frac{1-k}{r} V^{\prime}(\tilde{b}(k))<1$, which implies that the denominator is positive. To complete our proof of (iv), we next show that $\tilde{b}(k) \in\left[b_{0}, b_{1}\right]$ for all $k \in\left[b_{0} /\left(\pi_{s}-\pi_{f}\right)\right.$, $\left.\min \left[k_{2}, 1\right]\right]$. From $(i i)$ and $(i i i)$, we have that $\tilde{b}\left(b_{0} /\left(\pi_{s}-\pi_{f}\right)\right)=b_{0}$ and $\tilde{b}\left(b_{1} /\left(\pi_{s}-\pi_{f}\right)\right) \leq b_{1}$. Since $\tilde{b}$ is increasing in $k$ whenever $\tilde{b}(k) \in\left[b_{0}, b_{1}\right]$, it must be that $\tilde{b}(k) \in\left[b_{0}, b_{1}\right]$ for all $k \in\left[b_{0} /\left(\pi_{s}-\pi_{f}\right), b_{1} /\left(\pi_{s}-\pi_{f}\right)\right]$. It remains to be shown that for $k \in\left(b_{1} /\left(\pi_{s}-\pi_{f}\right), \min \left[k_{2}, 1\right]\right], \tilde{b}(k) \in\left[b_{0}, b_{1}\right]$. To establish this, we first note that if $\tilde{b}\left(b_{1} /\left(\pi_{s}-\pi_{f}\right)\right)=b_{1}$, then $\left.k_{2}=b_{1} /\left(\pi_{s}-\pi_{f}\right)\right)$.

Suppose, on the other hand, that $\tilde{b}\left(b_{1} /\left(\pi_{s}-\pi_{f}\right)\right)<b_{1}$. Then, as we showed in the proof of $(i i i), b_{1}$ is the largest solution to (7). Hence, when $k=b_{1} /\left(\pi_{s}-\pi_{f}\right)$, the the slope of the right side of $(7)$ at $b=b_{1}$ is greater than the slope of the left side. Since the slope of the right side of (7) at $b=b_{1}$ is increasing with $k$, the right side of (7) is steeper than the left at $b=b_{1}$ for all $k>b_{1} /\left(\pi_{s}-\pi_{f}\right)$. Convexity of $-V$ then implies that every solution to $(7)$ for $k>b_{1} /\left(\pi_{s}-\pi_{f}\right)$ must be less than $b_{1}$. We therefore have that $k_{2}>b_{1} /\left(\pi_{s}-\pi_{f}\right)$ and $\tilde{b}(k)<b_{1}$.

To establish $(v)$, we note that from the definition of $k_{2}, \tilde{b}$ is undefined for $k>k_{2}$. Hence $b^{f b}(k)=0 . \square$

\section{Proofs from Section 4.2}

An equilibrium fails the Cho and Kreps (1987) Intuitive Criterion if there is a type of sender $\theta$ that receives less than its equilibrium payoff by playing a particular action $a$ for all possible specifications of the receiver's beliefs conditional on $a$ and a type of sender $\theta^{\prime}$ that receives more than its equilibrium payoff when playing $a$ as long as the receiver assesses $\operatorname{Pr}(\theta \mid a)=0$. (See Fudenberg and Tirole (1995) for a discussion.) We show that if the market assesses probability zero to project success after observing a non-zero bonus payment, then there exists an equilibrium that fails the Intuitive Criterion. It follows that the only beliefs for which there are no equilibria that fail the Intuitive Criterion assess probability one to project success for any non-zero bonus payment.

Proposition 5 Fix $k$ and let $b^{r n}>0$. If the market assesses probability zero to project success when observing a bonus payment less than $b^{r n}$, then there exists an equilibrium that fails the Cho and Kreps (1987) Intuitive Criterion.

Proof: Fix $k$ and select an arbitrary $b^{r n}>0$. Let the market's beliefs as to the project outcome conditional on observing the firm's bonus payment be:

$$
\begin{aligned}
& \operatorname{Prob}\left[\text { success } \mid b \geq b^{r n}\right]=1 \\
& \operatorname{Prob}\left[\text { success } \mid b<b^{r n}\right]=0 .
\end{aligned}
$$

We first construct an equilibrium given these beliefs, and then show that this equilibrium fails the Intuitive Criterion. Under the assumption that reputational governance is in place, the largest 
equilibrium bonus payment (which we denote here as $b^{* *}$ ) is given by the largest solution to

$$
\frac{1}{r}\left(V\left(b^{* *}\right)-\max \left[0, V\left(b^{f b}(k)\right)\right]\right)=b^{* *}-b^{r n} .
$$

To apply the Intuitive Criterion, we first compare the equilibrium payoff to a firm with a failed project to the payoff when making a bonus payment $\beta=b^{r n}-\epsilon$ (where $\epsilon>0$ is arbitrarily small) assuming the market assesses the probability of success is one conditional on observing $\beta$. The equilibrium payoff to a firm with a failed project is given by $\pi_{f}+(1 / r) V\left(b^{* *}\right)$. If a firm with a failed project makes a bonus payment $\beta$ and the market assesses project success, then the fraction $k$ of original shareholders who sell their shares at the first round of trading receive the payoff due to a firm with a successful project that has broken its relational contract. The fraction $1-k$ who hold their shares earn $\pi_{f}$ in the current period, and, since the firm breaks its commitment not to pay bonuses for project success, earn the future payoff associated with the inability to pay output-contingent bonuses. The average payoff to the original shareholders is

$$
k\left(\pi_{s}-\beta+\frac{1}{r} \max \left[0, V\left(b^{f b}(k)\right)\right]\right)+(1-k)\left(\pi_{f}-\beta+\frac{1}{r} \max [0, V(0)]\right) .
$$

Rearranging (13), we have that a firm with a failed project prefers its equilibrium payoff to its payoff from paying $\beta$ if

$$
\frac{1}{r} V\left(b^{* *}\right)>k\left(\pi_{s}-\pi_{f}\right)+\frac{k}{r}\left(\max \left[0, V\left(b^{f b}(k)\right)\right]-\max [0, V(0)]\right)-\beta+\frac{1}{r} \max [0, V(0)] .
$$

Consider first the case where $b^{f b}(k)>0$. Given this, we have that

$$
b^{f b}(k)=k\left(\pi_{s}-\pi_{f}\right)-\frac{1-k}{r}\left(\max \left[0, V\left(b^{f b}(k)\right)\right]-\max [0, V(0)]\right) .
$$

We substitute (15) into (14), rearrange, and find that a firm with a failed project prefers its equilibrium payoff if

$$
\frac{1}{r}\left(V\left(b^{* *}\right)-\max \left[0, V\left(b^{f b}(k)\right)\right]\right)>b^{f b}(k)-\beta .
$$

Note that since reputational governance is in place, we have that $V\left(b^{* *}\right)>\max \left[0, V\left(b^{f b}(k)\right)\right]$, and hence that $b^{* *}>b^{f b}(k)$. Since $\beta$ can be made arbitrarily close to $b^{r n}$, we therefore have

$$
b^{* *}-b^{r n}>b^{f b}(k)-\beta .
$$

Together, (12) and (17) imply (16), so we have that a firm with a failed project prefers its equilibrium payoff to its payoff when paying $\beta$. Hence, if we can show that a firm with a successful project prefers its payoff when paying bonus $\beta$ assuming the market assesses $\operatorname{Prob}[$ success $\mid \beta]=1$ to its equilibrium payoff, then this equilibrium fails the Intuitive Criterion. For a firm with a successful project, the equilibrium payoff is

$$
\pi_{s}-b^{* *}+\frac{1}{r} V\left(b^{* *}\right)
$$


while the payoff when paying $\beta$ when the market assesses $\operatorname{Prob}[$ success $\mid \beta]=1$ is

$$
\pi_{s}-\beta+\frac{1}{r} \max \left[0, V\left(b^{f b}(k)\right)\right] .
$$

The firm prefers the payoff from paying $\beta$ if

$$
b^{* *}-\beta>\frac{1}{r}\left(V\left(b^{* *}\right)-\max \left[0, V\left(b^{f b}(k)\right)\right]\right)
$$

which is implied by (12) and the fact that $\beta<b^{r n}$. Hence, a firm with a failed project prefers its equilibrium payoff to its payoff from paying $\beta$ even if the market makes the most favorable possible inference based on $\beta$, and a firm with a successful project prefers to pay $\beta$ if the market assesses $\operatorname{Prob}[$ failure $\mid \beta]=0$. This equilibrium therefore fails the Intuitive Criterion.

Alternatively, suppose that $b^{f b}(k)=0$, and recall from Section 4 that $b^{f b}(k)=0$ only if $V(0)<0$. Hence, (14) reduces to

$$
\frac{1}{r} V\left(b^{* *}\right)>k\left(\pi_{s}-\pi_{f}\right)-\beta .
$$

Since $b^{f b}(k)=0$, it must be the case that $V\left(k\left(\pi_{s}-\pi_{f}\right)\right) \leq 0$. As we have assumed that reputational governance is in place, we have that $V\left(b^{* *}\right)>0$, which implies $b^{* *}>k\left(\pi_{s}-\pi_{f}\right)$. Also, since $\beta$ can be made arbitrarily close to $b^{r n}$, we have

$$
b^{* *}-b^{r n}>k\left(\pi_{s}-\pi_{f}\right)-\beta .
$$

Together, (12) and (19) imply (18), so we have that a firm with a failed project prefers its equilibrium payoff to its payoff when paying $\beta$. Since

$$
b^{* *}-\beta>\frac{1}{r} V\left(b^{* *}\right),
$$

a firm with a successful project prefers its payoff when paying bonus $\beta$ assuming the market assesses $\operatorname{Prob}[$ success $\mid \beta]=1$ to its equilibrium payoff. This equilibrium fails the Intuitive Criterion as well.

Since choice of $b^{r n}>0$ was arbitrary, we have now shown that for any market beliefs characterized by Prob[success $\left.\mid b \geq b^{r n}\right]=1$, there must exist an equilibrium that fails the Intuitive Criterion. $\square$

\section{Proofs from Section 4.2.2}

We restrict attention to equilibria featuring trigger strategies and focus on identifying the largest bonus amounts that are feasible under reputational governance. A strategy for the firm consists of one wage contract to be offered in the event that the firm has not breached past relational contracts (so that the history of play is cooperative), and another contract to be offered otherwise. After observing the firm's contract offer, the manager chooses whether to accept the offer, and if so, what level of effort to undertake. A strategy for the manager consists of two mappings from contract offers to contract acceptance and effort decisions: one mapping is used if play has been cooperative, while another is used 
otherwise. The manager plays a trigger strategy in which he trusts the firm's promise to pay bonuses as part of a relational contract if and only if the firm has not breached a relational contract in the past. If the firm has breached a relational contract in the past, then the manager assumes the firm will do so again.

We define Relational Contract-Signaling Equilibrium (RCSE) to consist of a strategy for the firm, a strategy for the manager, and a mapping from observed bonus payments and the history of play to market values that satisfies the following properties:

1. Taking the history of play, the mapping from wage payments and history to market values, and the manager's strategy as given, the firm's contract offer and choice of bonus payment must maximize the average payoff to original shareholders.

2. Taking the history of play, the mapping from wage payments and history to market values, and the firm's strategy as given, the manager's participation and effort decisions must maximize his expected utility.

3. The market's assessment of the value of the firm conditional on the observed bonus payment and the history of play must be correct.

4. Given a contract $(s, b)$, for all $b^{\prime}<b$ such that $\pi_{f}>k \pi_{s}+(1-k) \pi_{f}-b^{\prime}$,

$$
\Pi[s, b, 1,0]>\Pi\left[s\left(b^{\prime}\right), b^{\prime}, 1,0\right] .
$$

Condition (4) is a refinement that eliminates equilibria with "excessive" signaling.

We refer to the largest feasible bonus under an RCSE as the RCSE bonus, and attempt to characterize how the RCSE bonus varies with $k$. Our propositions here refer to the case studied in Section 4.2.2; proofs for the case studied in Section 4.2.1 are similar.

Proposition 6 Suppose $V(0)<0$. Then for $k \in\left[0, k_{0}\right)$, the RCSE bonus does not vary with $k$.

Proof: First note that in the event that the relational contract has been breached in the past, the firm elects not to offer a contract that will be accepted by the manager. The refinement of property (4) eliminates all equilibria with "excessive" signaling. Hence, the only bonus the firm can credibly offer is that characterized by the function $b^{f b}(k)$. Since (by Proposition 4$) b^{f b}(k)=0$ when $k \in\left[0, k_{0}\right.$ ) and $V(0)<0$, the firm is best off it does not offer a contract that will be accepted by the manager. Hence, the firm's profit in the fallback position is zero.

Given this, the bonuses feasible under reputational governance are those $b$ satisfying $V(b) \geq r b$. The RCSE bonus is the largest solution to this inequality, and since no term in this inequality varies with $k$, we have that the RCSE bonus does not depend on $k$ on this interval. $\square$

Proposition 7 Suppose $V(0) \geq 0$ and $k \in\left[0, k_{1}\right)$, or that $V<0$ and $k \in\left[k_{0}, k_{1}\right)$. For a given $k$ in this interval, if the RCSE bonus is greater than $b^{f b}(k)$, then the RCSE bonus is strictly decreasing in $k$ at 
that point. If the RCSE bonus is equal to $b^{f b}(k)$, then the RCSE bonus is strictly increasing in $k$ at that point.

Proof: In the event that the relational contract has been breached in the past, the firm can rely on the no-mimic constraint as a governance mechanism. Again since the refinement of property (4) eliminates equilibria with "excessive" signaling, the bonus that can be credibly offered in the fallback position is given by $b^{f b}(k)$. Since $k_{1}<k_{2}$, we have (from Proposition 4 ) that $b^{f b}(k)$ is strictly increasing with $k$ on this interval.

Given this, the reputational governance constraint is $V(b)-V\left(b^{f b}(k)\right) \geq r\left(b-b^{f b}(k)\right)$. If this inequality is satisfied for some $b$, then the RCSE bonus is the largest such solution. Since, by definition of $k_{1}$, $V(b)-V\left(b^{f b}(k)\right)$ decreases faster with $k$ on this interval than $r\left(b-b^{f b}(k)\right)$, the RCSE bonus decreases with $k$. If, on the other hand, the reputational governance constraint is not satisfied for any $b$, then the RCSE bonus is given by $b^{f b}(k)$, which is strictly increasing in $k$.

Proposition 8 Suppose $k \in\left[k_{1}, \min \left[k_{2}, 1\right]\right]$. The RCSE bonus is weakly increasing in $k$ over this interval.

Proof: Here, the firm can still rely on the no-mimic constraint as a governance mechanism in the event the relational contract is breached. As property (4) eliminates equilibria with "excessive" signaling, the bonus that can be credibly offered in the fallback position is given by $b^{f b}(k)$. Since $k \in\left[k_{0}, k_{2}\right]$, we have (from Proposition 4) that $b^{f b}(k)$ is strictly increasing with $k$ on this interval.

Given this, the reputational governance constraint is $V(b)-V\left(b^{f b}(k)\right) \geq r\left(b-b^{f b}(k)\right)$. If this inequality is satisfied for some $b$, then the RCSE bonus is the largest such solution. Since, by definition of $k_{1}$, $V(b)-V\left(b^{f b}(k)\right)$ decreases slower with $k$ on this interval than $r\left(b-b^{f b}(k)\right)$ does, the RCSE bonus increases with $k$. If, on the other hand, the reputational governance constraint is not satisfied for any $b$, then the RCSE bonus is given by $b^{f b}(k)$, which is strictly increasing. $\square$

Proposition 9 If $k_{2}<1$, then for $k \in\left(k_{2}, 1\right]$, the RCSE bonus does not vary with $k$.

Proof: First note that in the event that the relational contract has been breached in the past, then the firm either offers a contract featuring bonus zero, or elects not to offer a contract that will be accepted by the manager. This holds since (from Proposition 4 ), $b^{f b}(k)=0$ for $k \in\left(k_{2}, 1\right]$. If $V(0) \geq 0$, then the firm offers the full-insurance contract if the relational contract has been breached. If $V(0)<0$, then the firm prefers to shut down.

Given this, the bonuses feasible under reputational governance are those $b$ satisfying $V(b)-\max [0, V(0)] \geq$ $r b$. The RCSE bonus is the largest solution to this inequality. Since no term in this inequality varies with $k$, we have that the RCSE bonus does not depend on $k$ on this interval. 


\section{References}

Baker, G., Gibbons, R. and Murphy, K. J.: 1994, Subjective performance measures in optimal incentive contracts, Quarterly Journal of Economics 109, 1125-1156.

Bhattacharya, S.: 1979, Imperfect information, dividend policy, and "the bird in the hand" fallacy, Bell Journal of Economics 10, 233-244.

Bull, C.: 1987, The existence of self-enforcing implicit contracts, Quarterly Journal of Economics 102, $147-160$.

Bushman, R. M., Indjejikian, R. J. and Smith, A.: 1996, CEO compensation: The role of individual performance evaluation, Journal of Accounting and Economics 21, 161-193.

Cho, I.-K. and Kreps, D.: 1987, Signaling games and stable equilibria, Quarterly Journal of Economics 102, 179-221.

Fudenberg, D. and Tirole, J.: 1995, Game Theory, MIT Press, Cambridge, MA.

Hayes, R. M. and Schaefer, S.: 1999, Implicit contracts and the explanatory power of top executive compensation for future performance. Kellogg Graduate School of Management, Northwestern University.

Holmstrom, B.: 1983, Equilibrium long-term labor contracts, Quarterly Journal of Economics 98, 23-54.

Holmstrom, B. and Tirole, J.: 1993, Market liquidity and performance monitoring, Journal of Political Economy 101, 678-709.

Ittner, C. D., Larcker, D. F. and Rajan, M. V.: 1997, The choice of performance measures in annual bonus contracts, Accounting Review 72, 231-255.

Johnson, M. F., Porter, S. and Shackell, M. B.: 1997, Shareholder pressure and the structure of executive compensation. University of Michigan Business School.

Kanodia, C. and Lee, D.: 1998, Investment and disclosure: The disciplinary role of period performance reports, Journal of Accounting Research 36, 33-55.

Leland, H. and Pyle, D.: 1977, Informational asymmetries, financial structure and financial intermediation, Journal of Finance 32, 371-387.

Levin, J.: 1998, Relational incentive contracts. MIT Department of Economics.

Miller, M. H. and Rock, K.: 1985, Dividend policy under asymmetric information, Journal of Finance 40, 1031-1051.

Murphy, K. J.: 1992, Politics, economics and executive compensation, Cincinnati Law Review 60, 223253. 
Perry, T. and Zenner, M.: 1998, Pay for performance? Government regulation and the structure of compensation contracts. The Kenan-Flagler Business School, University of North Carolina at Chapel Hill.

Quinn, L. C.: 1995, Proceedings of the 1994 corporate law symposium, Cincinnati Law Review 63, 769815 .

Ross, S. A.: 1977, The determination of financial structure: The incentive-signaling approach, Bell Journal of Economics 8, 23-40.

Stein, J. C.: 1988, Takeover threats and managerial myopia, Journal of Political Economy 96, 61-80. 